\title{
On the interaction of delamination buckling and damage growth in cross-ply laminates
}

\author{
Anton Köllner ${ }^{\mathrm{a}, \mathrm{c}, *}$, Maria Kashtalyan ${ }^{\mathrm{b}}$, Igor Guz ${ }^{\mathrm{b}}$, Christina Völlmecke ${ }^{\mathrm{a}}$ \\ ${ }^{a}$ Technische Universität Berlin, Institute of Mechanics, Stability and Failure of Functionally \\ Optimized Structures Group, Einsteinufer 5, 10587 Berlin, Germany. \\ ${ }^{b}$ University of Aberdeen, School of Engineering, Centre for Micro- and Nanomechanics, Aberdeen \\ AB24 3UE, United Kingdom. \\ ${ }^{c}$ Imperial College London, Department of Civil and Environmental Engineering, Structures \\ Section, London SWr 2AZ, United Kingdom.
}

\begin{abstract}
The compressive behaviour of cross-ply laminates with delaminations and matrix cracked layers is investigated by means of an analytical modelling approach. Insight into the post-buckling and damage growth behaviour is obtained owing to comprehensive parametric studies varying delamination length and depth as well as matrix crack density for cross-ply laminates with different layups. The efficient modelling approach comprises the well-known total potential energy principle and the Equivalent Constrained Model for determining reduced stiffness properties depending on the matrix crack density. Thus, unlike previous studies on delamination buckling, the effect of matrix cracked layers is taken into consideration. The analysis of the energy release rates for delamination and matrix crack growth enables the identification of configurations (e.g. delamination depth and length, total thickness of the laminates) which are prone to delamination growth and matrix crack growth, respectively. Beyond that, relationships between post-buckling and damage growth behaviour are identified and discussed.
\end{abstract}

Keywords: delamination buckling, matrix cracks, energy release rate, post-buckling, cross-ply laminates, BVID

\footnotetext{
${ }^{*}$ Corresponding author

Email address: a.koellner@imperial.ac.uk (Anton Köllner)
} 


\section{Introduction}

Recently, the study of the compressive behaviour of delaminated composite structures has been revived, where analytical [5, 17, 20, 22, 31, 38, 39], numerical $[1,25,26,27,35,36]$ as well as experimental efforts $[10,31,32,35]$ have been made to provide more insight into the (post-)buckling and damage growth behaviour. Most of the work is put into context towards analysing the compressive response of composite panels exhibiting barely visible impact damage (BVID), which constitutes an application example of particular interest to the aircraft/aerospace industry [3].

Current analytical modelling approaches mainly pursue two objectives:

- prediction of the onset of delamination growth for standard and non-standard layups as well local and local-global buckling responses (e.g. [3, 17, 31]), and

- modelling post-buckling deformation considering delamination growth (e.g. [20, $22,38])$.

Numerical work considers in general more comprehensive damage scenarios originating from modelled impact loading (e.g. [1, 35, 36]). However, efforts have also been made to provide effective numerical simulations (e.g. [26, 27]) aiming at post-buckling deformations and delamination growth of distinctly delaminated laminates. Experimental work comprises either artificially placed delaminations (e.g. $[3,10])$ or impacted laminates (e.g. $[32,35])$.

Whenever analytical approaches aim at predicting the compressive strength of damaged slender composite panels, it is argued that such strength is associated with delamination buckling, and thus delamination propagation, of one dominant delamination ( $c f$. $[31,38]$ ). While this may prove correct for many cases, this study aims at exploring whether matrix crack growth should be considered when investigating delamination buckling or not. Besides that, the objective of the work is to provide detailed insight into the relationship of post-buckling responses and damage growth characteristics, which has not received much attention yet. Previous (semi-)analytical studies investigated delamination growth by considering specific types of buckling [33] (e.g. open-mode buckling), isotropic behaviour [9, 34] or orthotropic and homogeneous struts $[4,40]$. The behaviour of the energy release rate has been described for certain configurations (e.g. relative delamination lengths 
and depths) [11, 40], however, a complete overview of the characteristics given and in particular its relation with post-buckling responses appears to be missing. On the other hand, the work also aims at providing an initial step into modelling the structural stability behaviour of composite panels exhibiting multiple distinct active damage mechanisms, which may pave the way to more realistic analytical modelling approach of BVID composite panels. To date, only multiple delaminations have been investigated by analytical modelling approaches, where mainly the buckling behaviour has been analysed [8] and only few attempts are documented studying delamination growth characteristics (e.g. [24]).

Owing to the complexity of the structural response of damaged composite panels, where minor changes in the configuration may cause a change in the qualitative behaviour [20], special interest lies in analytical modelling approaches owing to the capability to perform comprehensive parametric studies. The current work presents an analytical modelling approach of the compressive behaviour of slender cross-ply laminates, which considers both delaminations and matrix cracked layers. The approach merges the total potential energy principle employed to model the post-buckling responses and the Equivalent Constrained Model (ECM) to derive stiffness degradations owing to matrix cracked layers into a single formulation. This yields an efficient analysis tool to capture the post-buckling, delamination and matrix crack growth behaviour of damaged composite panels.

An initial step of the authors towards such a modelling approach can be found in [19], where focus has been placed on modelling post-buckling paths during delamination growth under the presence of matrix cracks rather than analyzing the damage growth behaviour in a generalized manner. In the current work, a comprehensive parametric study, varying the thickness of the laminate, delamination depth and length as well as matrix crack density, is performed. The outcome of the study is a detailed analysis of the stability behaviour as well as the damage growth behaviour, which clearly determines

- types of post-buckling responses,

- regions where the respective failure mechanisms (delamination growth, matrix crack growth) are dominant,

as well as the interaction between 
- types of post-buckling response and damage growth behaviour, and

- delamination and matrix crack growth.

First, the Equivalent Constrained Model and the energy formalism are described in Section 2. Subsequently, the results of the comprehensive parametric study are presented in Section 3, followed by a discussion (Section 4) and conclusions (Section $5)$.

\section{Modelling approach}

The analytical modelling approach consists of two parts:

- the derivation of reduced stiffness properties depending on the matrix crack density present in the respective layers as well as

- an energy formalism, so that post-buckling deformation for delaminated composite plates can be determined.

The former is described in Section 2.1 and provides analytical expressions for the stiffness properties of cracked layers which are incorporated in the energy formalism comprising the total potential energy principle and the calculation of the energy release rates, described in Section 2.2.

\subsection{Equivalent Constrained Model}

When a cross-ply laminate $\left(e . g .\left[\left(0^{\circ} / 90^{\circ}\right)_{\mathrm{s}}\right]_{n}\right)$ contains matrix cracks in a $90^{\circ}$ layer (Fig. 1(left)), their presence can be accounted for by replacing the actual cracked layer with an equivalent homogeneous layer possessing degraded stiffness properties (Fig. 1(middle)), which can be determined in closed form with the help of the Equivalent Constraint Model ( $c f .[13,14,41])$.

To determine the effective stiffness properties of the cracked $90^{\circ}$ layer, an equivalent $\left[0^{\circ} / 90^{\circ}\right]_{\mathrm{s}}$ cross-ply laminate is considered with a ply thickness equal to half ply thickness of the original $90^{\circ}$ layer (Fig. 1(right)). In this way, the constraining effect of the immediate neighbouring layers on the cracked ply is taken into account, while the constraining effect of the remote constraining layers, which was shown to be negligible ( $c f$. [42]), can be ignored. 


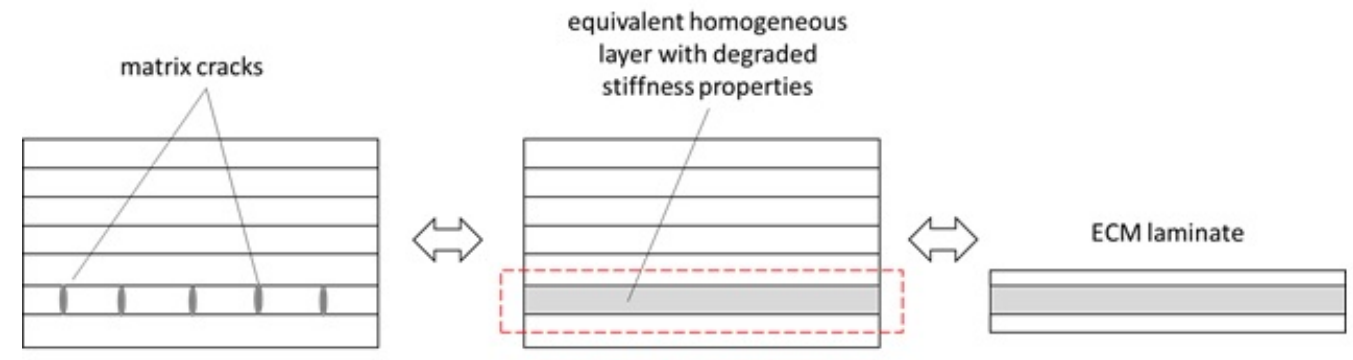

Figure 1: Composite laminate containing matrix cracks (left); Composite laminate with equivalent homogeneous layer (middle); Equivalent Constraint Model laminate (right).

In the local coordinate system of the $90^{\circ}$ layer, the reduced in-plane stiffness matrix of the equivalent homogeneous layer $\left(\left[\bar{Q}^{(90)}\right]\right)$ can be represented in terms of the in-plane stiffness matrix of the undamaged layer $\left(\left[\hat{Q}^{(90)}\right]\right)$ via the In-situ Damage Effective Functions (IDEFs) (cf. [41]) as

$$
\left[\bar{Q}^{(90)}\right]=\left[\hat{Q}^{(90)}\right]-\left[\begin{array}{ccc}
\frac{\left(\hat{Q}_{12}^{(90)}\right)^{2}}{\hat{Q}_{22}^{(90)}} \Lambda_{22}^{(90)} & \hat{Q}_{12}^{(90)} \Lambda_{22}^{(90)} & 0 \\
\hat{Q}_{12}^{(90)} \Lambda_{22}^{(90)} & \hat{Q}_{22}^{(90)} \Lambda_{22}^{(90)} & 0 \\
0 & 0 & \hat{Q}_{66}^{(90)} \Lambda_{66}^{(90)}
\end{array}\right]
$$

The In-situ Damage Effective Functions (IDEFs) $\left(\Lambda_{22}^{(90)}, \Lambda_{66}^{(90)}\right)$ are explicit functions of the relative transverse crack density,

$D=\frac{h^{(90)}}{s}$

where $h^{(90)}$ and $s$ are the thickness of the $90^{\circ}$ layer and half the distance in between two matrix cracks respectively, in the form

$$
\Lambda_{22}^{(90)}=\frac{1-\frac{D}{\lambda_{1}^{(90)}} \tanh \left(\frac{\lambda_{1}^{(90)}}{D}\right)}{1+\alpha_{1}^{(90)} \frac{D}{\lambda_{1}^{(90)}} \tanh \left(\frac{\lambda_{1}^{(90)}}{D}\right)} \quad \text { and } \quad \Lambda_{66}^{(90)}=\frac{1-\frac{D}{\lambda_{2}^{(90)}} \tanh \left(\frac{\lambda_{2}^{(90)}}{D}\right)}{1+\alpha_{2}^{(90)} \frac{D}{\lambda_{2}^{(90)}} \tanh \left(\frac{\lambda_{2}^{(90)}}{D}\right)} .
$$

The constants $\lambda_{i}^{(90)}=h^{(90)} \sqrt{L_{i}^{(90)}}$ and $\alpha_{i}^{(90)}$, depend solely on the compliances $\hat{S}_{I J}^{(0)}$, $\hat{S}_{I J}^{(90)}$ of the undamaged $0^{\circ}$ and $90^{\circ}$ layers respectively $(\{I, J\}=\{1,2,3,4,5,6\})$, 
the shear lag parameters $K_{j}$ and the layer thickness ratio $\chi=h^{(0)} / h^{(90)}$ as follows (cf. [12]):

$$
\begin{aligned}
L_{1}^{(90)} & =\frac{K_{2}}{h^{(0)}}\left(\hat{S}_{22}^{(0)}+\chi \hat{S}_{22}^{(90)}+a_{1}\left(\hat{S}_{12}^{(0)}+\chi \hat{S}_{12}^{(90)}\right)\right), \\
L_{2}^{(90)} & =\frac{K_{1}}{h^{(0)}}\left(\hat{S}_{66}^{(0)}+\chi \hat{S}_{66}^{(90)}\right), \\
a_{1} & =-\frac{\hat{S}_{12}^{(0)}+\chi \hat{S}_{12}^{(90)}}{\hat{S}_{11}^{(0)}+\chi \hat{S}_{11}^{(90)}}, \\
\alpha_{1}^{(90)} & =\frac{1}{\chi}\left(\hat{Q}_{22}^{(90)}\left(\hat{S}_{22}^{(0)}+a_{1} \hat{S}_{12}^{(0)}\right)+\left(\hat{Q}_{12}^{(90)} \hat{S}_{12}^{(0)}+a_{1} \hat{S}_{11}^{(0)}\right)\right), \\
\alpha_{2}^{(90)} & =\frac{1}{\chi} \hat{Q}_{66}^{(90)} \hat{S}_{66}^{(90)}, \\
K_{j} & =\frac{3 G_{j 3}^{(0)} G_{j 3}^{(90)}}{h^{(90)} G_{j 3}^{(0)}+(1+(1-\eta) / 2) \eta h^{(0)} G_{j 3}^{(90)}}, \quad \text { with } \quad j=\{1,2\},
\end{aligned}
$$

where $G_{j 3}^{(0)}$ and $G_{j 3}^{(90)}$ are the out-of plane shear stiffness of the $0^{\circ}$ and $90^{\circ}$ layer respectively. The parameter $\eta=h_{\mathrm{s}} / h^{(0)}$ describes a thickness ratio of the shear layer and the $0^{\circ}$ layer [12].

\subsection{Energy formalism and energy release rates}

The study considers delaminated composite struts which may be regarded as one-dimensional representations of composite plates with a through-the-width delamination ( $c f$. Fig. 2). The formalism follows $[18,20]$ in which the post-buckling behaviour during delamination propagation has been investigated.

As can be seen in Fig. 2, the strut is subdivided into four parts. Each part is given its own coordinate system. Parts (1) and (2) are the upper and lower sublaminate respectively. Parts (3) and (4) describe the undelaminated region of the strut. Subsequently, owing to the symmetry, part (3) is considered for the undelaminated region only. The length of the central delamination is denoted by $L$ and the delamination depth by the parameter $a$ providing a ratio between thickness of the upper sublaminate (part (1)) and the total thickness of the strut $t$ (part (3)). The total length of the strut $L_{\text {tot }}$ will subsequently be used to provide a normalized measure of the delamination length, i.e.: $L_{\text {norm }}=L / L_{\text {tot }}$.

Besides the delamination, it is assumed that the strut exhibits a matrix cracked 


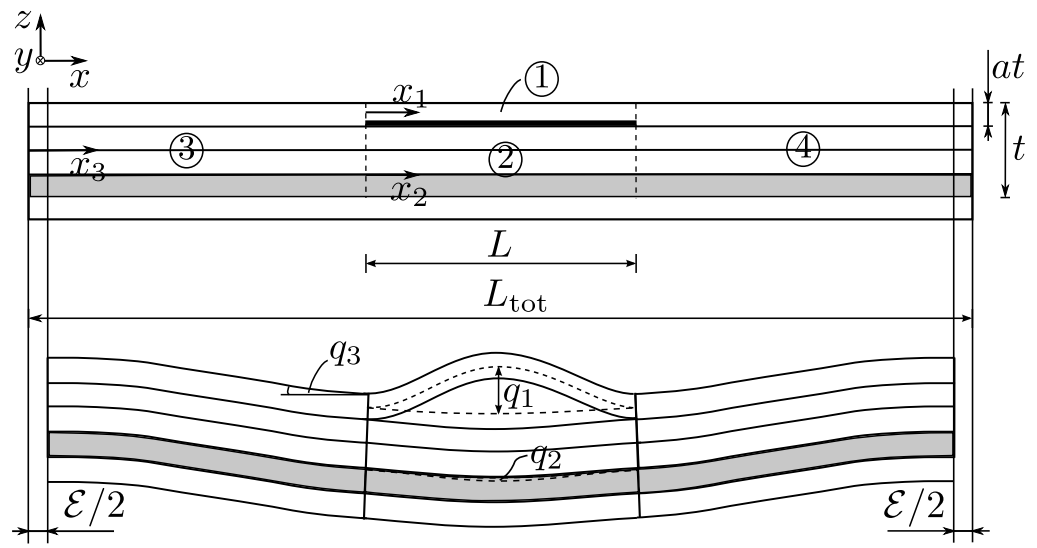

Figure 2: (a) One-dimensional model of a composite strut with a through-the-width delamination (adapted from [20]).

layer. The cracked layer with the matrix crack density $D(c f$. Eq. (2)) is assumed to be present in the most outward $90^{\circ}$ layer, which is exemplarily illustrated in Fig. 2 by highlighting the respective layer in grey.

Four generalized coordinates are employed to describe the system $(c f .[16,21])$ :

- $q_{1}, q_{2}$ : amplitude of the out-of-plane displacement of the upper and lower sublaminate, respectively,

- $q_{3}$ : rotation at the interface between intact and delaminated region,

- $q_{4}$ : shortening of the delaminated region.

In contrast to $[20,21]$, in-plane stretching of the delaminated region is also considered, which is required owing to the addition of matrix cracked layers to the model. However, no further generalized coordinate is introduced, since a displacement controlled configuration is employed with $\mathcal{E}$ denoting the applied end-shortening of the strut ( $c f$. Fig. 2). Thus, the shortening of the intact region is simply obtained by the difference between $\mathcal{E}$ and $q_{4}$.

The total potential energy, i.e. the strain energy (displacement controlled configuration), is derived using the Classical Laminate Theory [30] in which coupling effects due to asymmetric layups caused by the delamination as well as reduced 
stiffness parameters due to matrix cracks are considered. A Rayleigh-Ritz formulation is employed considering the geometric boundary and continuity conditions $[21]$,

$$
\begin{array}{ll}
w^{(3)}\left(x_{3}=0\right)=0, & w^{(3)}\left(x_{3}=s L\right)=w^{(i)}\left(x_{i}=0\right), \\
w^{(3)}\left(x_{3}=L_{\mathrm{tot}}\right)=0, & w^{(3)}\left(x_{3}=s L+L\right)=w^{(i)}\left(x_{i}=L\right), \\
\left(w^{(3)}\right)^{\prime}\left(x_{3}=0\right)=0, & \left(w^{(3)}\right)^{\prime}\left(x_{3}=s L\right)=\left(w^{(i)}\right)^{\prime}\left(x_{i}=0\right), \\
\left(w^{(3)}\right)^{\prime}\left(x_{3}=L_{\mathrm{tot}}\right)=0, & \left(w^{(3)}\right)^{\prime}\left(x_{3}=s L+L\right)=\left(w^{(i)}\right)^{\prime}\left(x_{i}=L\right),
\end{array}
$$

with $i=1,2$ and $s=1 / 2\left(L_{\text {tot }} / L-1\right)$. In Eq. (5), clamped boundary conditions are considered and a $(\bullet)^{\prime}$ denotes a differentiation with respect to the $x$ coordinate of the respective part. The buckling displacement of each part (1)-(3) is approximated as follows:

$$
\begin{gathered}
w^{(i)}=q_{i} \sin ^{2}\left(\frac{\pi x_{i}}{L}\right)+C_{0} x_{i}^{3}+C_{1} x_{i}^{2}+C_{2} x_{i}+C_{3} \quad \text { with } i=1,2 \text { and } \\
C_{0}=\frac{q_{3}}{2 L^{3}}\left(\frac{L_{\text {tot }}}{\pi} \tan \left(\frac{\pi s L}{L_{\text {tot }}}\right)-\frac{L_{\text {tot }}}{\pi \cos \left(\frac{\pi s L}{L_{\text {tot }}}\right)} \sin \left(\frac{\pi(s L+L)}{L_{\text {tot }}}\right)\right), \\
C_{1}=\frac{1}{2}\left(-\frac{2 q_{3}}{L}-3 C_{0} L\right), \\
C_{2}=q_{3}, \quad C_{3}=\frac{q_{3} L_{\text {tot }}}{2 \pi} \tan \left(\frac{\pi s L}{L_{\text {tot }}}\right), \\
w^{(3)}=q_{3} \frac{L_{\text {tot }}}{2 \pi \cos \left(\frac{\pi s L}{L_{\text {tot }}}\right) \sin \left(\frac{\pi s L}{L_{\text {tot }}}\right)} \sin ^{2}\left(\frac{\pi x_{3}}{L_{\text {tot }}}\right),
\end{gathered}
$$

employing the solution of the given Euler case (both sided clamped strut) as well as a polynomial. ${ }^{1}$ The coefficients of the polynomial $\left(C_{0 \ldots 3}\right)$ are determined such that the geometric boundary and the continuity conditions for the buckling displacements ( $c f$. Eq. (5)) are enforced.

The model employs a non-linear kinematic approach, as documented in [9], to

\footnotetext{
${ }^{1}$ Note that the sublaminates are treated as being clamped in the intact region of the strut.
} 
describe the axial shortening of the delaminated $\left(u^{(1)}, u^{(2)}\right)$ and intact region $\left(u^{(3)}\right)$ :

$$
\begin{aligned}
& u^{(1)}=q_{4}-\frac{1}{2} \int_{0}^{L}\left(\frac{\partial w^{(1)}}{\partial x_{1}}\right)^{2} \mathrm{~d} x_{1}-2\left(\frac{1-a}{2}\right) t q_{3}, \\
& u^{(2)}=q_{4}-\frac{1}{2} \int_{0}^{L}\left(\frac{\partial w^{(2)}}{\partial x_{2}}\right)^{2} \mathrm{~d} x_{2}+2\left(\frac{a}{2}\right) t q_{3}, \\
& u^{(3)}=\left(\mathcal{E}-q_{4}\right)-\frac{1}{2} \int_{0}^{s L}\left(\frac{\partial w^{(3)}}{\partial x_{3}}\right)^{2} \mathrm{~d} x_{3},
\end{aligned}
$$

from which, assuming evenly distributed strain [9], the respective in-plane strains $\left(\varepsilon_{0}^{(1)}, \varepsilon_{0}^{(2)}, \varepsilon_{0}^{(3)}\right)$ are obtained by simple division with the respective length of the parts.

The strain energy $W$ combines energy contributions from stretching and bending deformations for each part of the strut, thus

$$
\begin{aligned}
W\left(q_{i}, \mathcal{E}, L, D\right)= & \frac{1}{2} b\left(2 \int_{0}^{s L}\left(D_{\text {eff }}^{(3)}\left(\left(w^{(3)}\right)^{\prime \prime}\right)^{2}+A_{\text {eff }}^{(3)}\left(\varepsilon_{0}^{(3)}\right)^{2}+2 B_{\text {eff }}^{(3)}\left(w^{(3)}\right)^{\prime \prime} \varepsilon_{0}^{(3)}\right) \mathrm{d} x_{3}+\right. \\
& \int_{0}^{L}\left(D_{\text {eff }}^{(1)}\left(\left(w^{(1)}\right)^{\prime \prime}\right)^{2}+A_{\text {eff }}^{(1)} \varepsilon_{0}^{(1)}+2 B_{\text {eff }}^{(1)}\left(w^{(1)}\right)^{\prime \prime} \varepsilon_{0}^{(1)}\right) \mathrm{d} x_{1}+ \\
& \left.\int_{0}^{L}\left(D_{\text {eff }}^{(2)}\left(\left(w^{(2)}\right)^{\prime \prime}\right)^{2}+A_{\text {eff }}^{(2)} \varepsilon_{0}^{(2)}+2 B_{\text {eff }}^{(2)}\left(w^{(2)}\right)^{\prime \prime} \varepsilon_{0}^{(2)}\right) \mathrm{d} x_{2}\right)
\end{aligned}
$$

in which $b$ denotes the width of the strut and a prime $(\bullet)^{\prime}$ a differentiation with respect to $x$ of the respective part of the strut. In Eq. (8), entries responsible for stretching-shearing $\left(A_{16}, A_{26}\right)$ and stretching-stretching $\left(A_{12}\right)$, stretching-twisting $\left(B_{16}, B_{26}\right)$ and stretching-bending $\left(B_{12}\right)$ as well as bending-twisting $\left(D_{16}, D_{26}\right)$, bending-bending $\left(D_{12}\right)$ are considered and incorporated by calculating effective parameters for in-plane $\left(A_{\text {eff }}\right)$, coupling $\left(B_{\text {eff }}\right)$ and bending $\left(D_{\text {eff }}\right)$ stiffness of the respective parts $(c f .[16]) .^{2}$ The effective stiffness parameters depend on the matrix

\footnotetext{
${ }^{2}$ Since the current work studies cross-ply laminates, the stiffness entries $(\bullet)_{16}$ and $(\bullet)_{26}$ are zero. Thus, the effective parameters consider stretching-stretching, stretching-bending, and bending-bending coupling. Ref. [16] provides formulae for full coupling.
} 
crack density $D$ and the delamination length is present in the curvatures (2nd derivatives of $w^{(i)}$ in Eq. (8)) and strains.

The post-buckling responses are obtained by determining the deformation paths $q_{i}(\mathcal{E})$ for the conservative system (i.e. damage parameters $L$ and $D$ are considered fixed) which are found by solving the non-linear set of algebraic equations

$\frac{\partial W}{\partial q_{i}}=0$

resulting from the condition that the first variation of the total potential energy vanishes, i.e. $\delta W=0$, if the system is in an equilibrium state. The calculation has been performed numerically using the software Mathematica, implementing a Newton-Raphson method. By varying the parameters delamination length $L$ and depth $a$ as well as matrix crack density $D$, the post-buckling behaviour of delaminated cracked cross-ply laminates is obtained.

The damage growth behaviour is determined by calculating the energy release rates for delamination growth $G_{\mathrm{del}}$, i.e.

$G_{\text {del }}=-\frac{\partial W}{\partial A_{\text {del }}}=-\frac{1}{b} \frac{\partial W}{\partial L}$

and matrix crack growth $G_{\mathrm{mc}}$, i.e.

$G_{\mathrm{mc}}=-\frac{\partial W}{\partial A_{\mathrm{mc}}}=-\frac{1}{b L_{\mathrm{tot}}} \frac{\partial W}{\partial D}$

where $A_{\text {del }}$ and $A_{\mathrm{mc}}$ are the delamination and matrix cracked area respectively. In the current work, it is assumed that the derivatives in Eqs. (10) and (11) exist and can be determined throughout the deformation process considered, i.e. changes to the contact state at the debonded interface are not considered. This assumption is valid for delaminated struts, i.e. through-the-width delaminations, where buckling deformations do not tend to cause contact of sublaminates in the vicinity of the delamination tip. ${ }^{3}$ However, if embedded delaminations would be studied, contact

\footnotetext{
${ }^{3}$ Note that in closed mode responses presented in Section 3 either the thinner less stiff sublaminate exhibits larger out-of-plane displacements than the thicker sublaminate ( $c f$. Type B) or the calculation is stopped when both sublaminates get in contact with each other (cf. Type A).
} 
in the debonded interface close to the delamination boundary may occur ( $c f .[28]$ ) and the assumption made would need to be revised.

The deformation path $q_{i}(\mathcal{E})$ obtained from solving Eq. (9) for a chosen delamination length and matrix crack density is inserted into Eqs. (10) and (11) yielding the energy release rates as function of the applied end-shortening (for the respective delamination length and the matrix crack density). A comprehensive parametric study is performed varying delamination length, delamination depth and matrix crack density. As a result the behaviour of the energy release rates can be described against a change in the damage parameters $(L$ and $D)$ and applied end-shortening.

\section{Results}

Cross-ply laminates with the stacking sequence $\left[\left(0^{\circ} / 90^{\circ}\right)_{\mathrm{s}}\right]_{n}$ are investigated. The dimensions and material parameters are provided in Table 1.

\begin{tabular}{c|c|c|c}
\multicolumn{2}{c|}{ Dimensions } & \multicolumn{2}{c}{ Material Parameters } \\
\hline$L_{\text {tot }}$ & $96.52 \mathrm{~mm}$ & $E_{11}$ & $137.90 \mathrm{GPa}$ \\
\hline$b$ & $12.70 \mathrm{~mm}$ & $E_{22}$ & $8.98 \mathrm{GPa}$ \\
\hline$h$ & $0.0889 \mathrm{~mm}$ & $G_{12}$ & $7.20 \mathrm{GPa}$ \\
\hline$a$ & $\{1 / m, 3 / m, 5 / m\}$ & $\nu_{12}$ & 0.30 \\
\hline$n$ & $\{5,6,7\}$ & $G_{\mathrm{c}}^{\mathrm{I}}$ & $0.19 \mathrm{~N} / \mathrm{mm}$ \\
\hline
\end{tabular}

Table 1: Dimensions and material parameters of the plate studied; taken from [20, 33].

Three laminates are considered, i.e.: $n=\{5,6,7\}$, resulting in 20,24 and 28 layers, respectively. Note that the total number of plies in a laminate will subsequently be denoted by parameter $m$. Delaminations at the interface of layers with different fibre orientation are considered. Therefore, the study investigates delaminations in between the first and second layer (delamination depth $a=1 / m$ ), the third and fourth layer $(a=3 / m)$ as well as the fifth and six layer $(a=5 / m){ }^{4}$

\footnotetext{
${ }^{4}$ For reasons of clarity, with regards to the delamination depth only, layers are counted starting from the top of the strut. Note that for determining the stiffness matrices in Eq. (8) the layer count starts from the bottom of the laminate.
} 
Thus, as indicated in Table 1, nine different delamination depths are investigated, i.e. $a=\{0.036,0.042,0.050,0.107,0.125,0.150,0.179,0.208,0.250\}$.

The delamination lengths and matrix crack densities investigated are $L=$ $\{2,4,6, \ldots, 70\} \mathrm{mm}$ and $D=\{0.05,0.1,0.15, \ldots, 1\}$. As a result, 700 simulations per delamination depth, i.e. 6300 in total, have been performed providing insight into the effect of delamination length and depth as well as matrix cracks on the postbuckling and damage growth behaviour. Beyond that, the step size of delamination length has been reduced to $1 \mathrm{~mm}$ for regions which exhibit an abrupt changeover in the post-buckling and damage growth behaviour (total number of simulations: $6500)$.

The matrix cracked layers have been assigned to the opposite site of the delamination assuming that stretching deformation originating from global buckling responses may cause matrix crack growth. Test runs assigning cracked layers throughout the laminates have confirmed this assumption. Note that matrix cracks spread over both $90^{\circ}$ layers of the $\left[0^{\circ} / 90^{\circ} / 90^{\circ} / 0^{\circ}\right]$ stacking sequence. It has been further observed that matrix cracks at deeper layers are not relevant for delamination buckling.

Throughout Section 3, the following normalization are performed: load (and also end-shortening) against the respective Euler load of an intact strut; midpoint deflection against the thickness of the struts; delamination length against the total length of the strut.

\subsection{Validation of the model}

\subsubsection{Post-buckling and damage growth}

The energy formalism described in Section 2.2 has been validated in previous work of the authors by comparisons against findings provided in the literature as well as finite element simulations ( $c f .[20,21,22])$. For the problem studied in the current work, findings for all types of post-buckling responses occurring for delaminated composite struts (discussed in detail in Section 3.2) are compared with finite element (FE) simulations performed in Abaqus. Therefore, the strut is built-up by shell elements (type S4R) with an element size of $0.4 \mathrm{~mm}$. The mesh is refined around the delamination tips to the size of the thickness of a single ply. In the FEM, the energy release rate is obtained by employing the virtual crack closure 
technique [23]. In the modelling approach and the FEM a mode I crack growth criterion, i.e. growth occurs whenever $G \geq G_{\mathrm{c}}^{\mathrm{I}}$, is implemented, which constitutes a conservative measure ( $c f$. discussion in Section 4). Further information about the FE model is provided in Appendix D.

In Fig. 3, deformation paths in the form of normalized compressive load ( $\left.P_{\text {norm }}\right)$ against midpoint deflection of upper (solid line) and lower (dashed line) sublaminates $\left(w_{\text {norm }}\right)$ are presented. For all types of post-buckling responses, the agreement between the modelling approach and FEM is very good. Post-buckling responses exhibiting stable (blue, black, green and light grey lines) and unstable (red and dark grey lines) behaviour as well as deformation states causing contact (symbol $\diamond$ ) between sublaminates or damage growth (symbol $\square$ ) almost coincide between the modelling approach and FEM. The maximum deviation in load causing damage growth is $2 \%$ (blue line) indicating that the modelling approach can cover all mechanical characteristics of interest.

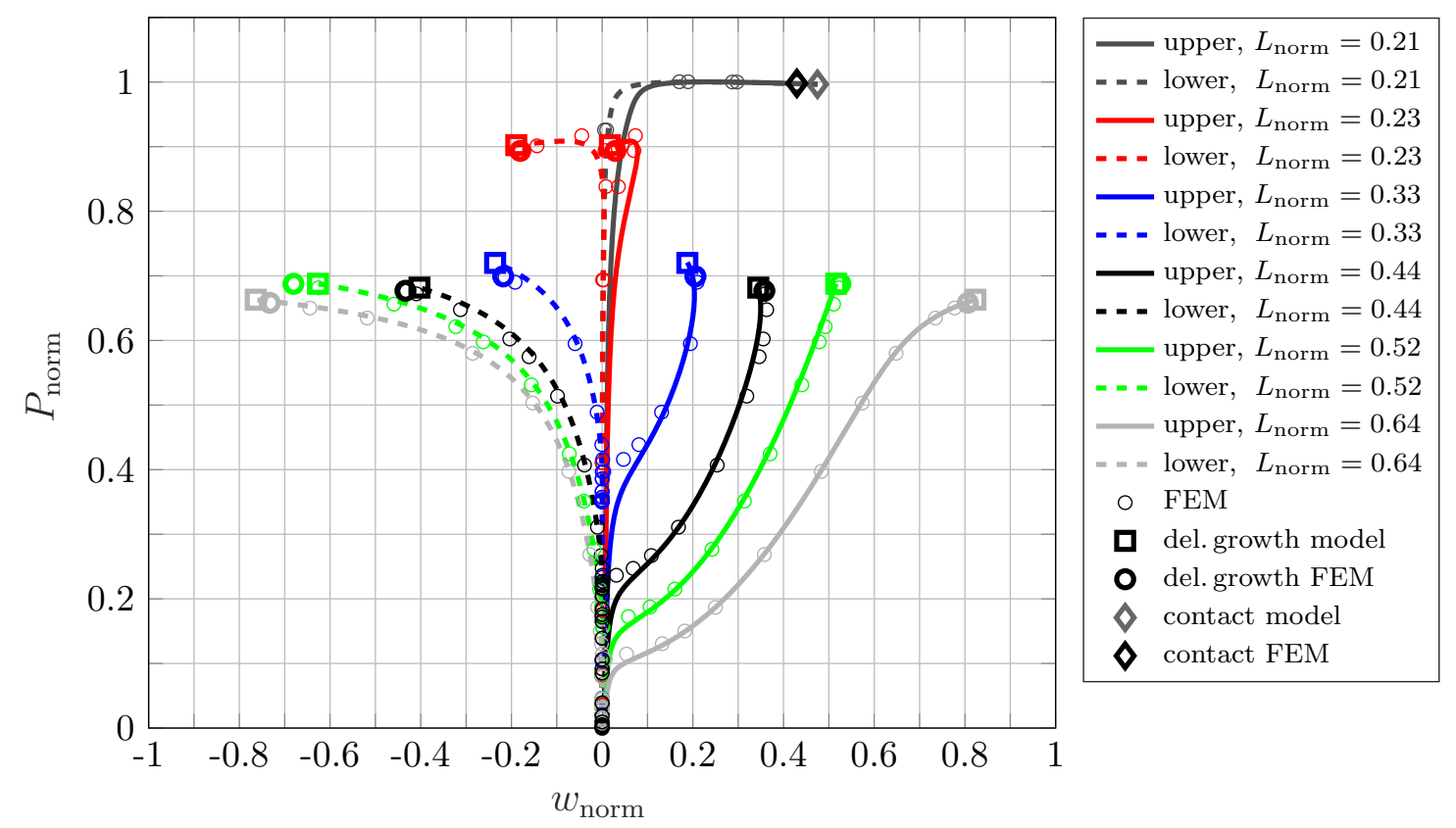

Figure 3: Comparison of the analytical model and FEM for characteristic post-buckling responses in the form of compressive load $\left(P_{\text {norm }}\right)$ against midpoint deflection $\left(w_{\text {norm }}\right)$. 


\subsubsection{Stiffness reduction due to matrix crack growth}

The Equivalent Constraint Model has been extensively validated through comparison with other analytical models as well as experimental data (cf. $[12,15])$. Table 2 shows comparison of the YounG's modulus reduction for GFRP and CFRP cross-ply laminates as predicted by Refs. [6, 7] and the ECM, with the ECM-based predictions being closer to the lower bound established by Hashin [6] than those of Ref. [7]. Comparisons of predicted reductions of the Poisson's ratio and shear modulus, as well as the material properties of GFRP and CFRP laminates used for validation purposes, are given in [12].

\begin{tabular}{c|c|c|c||c|c|c} 
damage parameter & \multicolumn{3}{|c||}{ GFRP } & \multicolumn{3}{c}{ CFRP } \\
\cline { 2 - 7 }$D$ & Ref. [6] & ECM & Ref. [7] & Ref. [6] & ECM & Ref. [7] \\
\hline 0.02 & 0.990 & 0.992 & 0.999 & 0.999 & 0.999 & 0.999 \\
\hline 0.05 & 0.976 & 0.981 & 0.993 & 0.997 & 0.998 & 0.999 \\
\hline 0.1 & 0.953 & 0.963 & 0.980 & 0.994 & 0.995 & 0.998 \\
\hline 0.2 & 0.910 & 0.928 & 0.957 & 0.989 & 0.991 & 0.995 \\
\hline 0.33 & 0.859 & 0.889 & 0.928 & 0.982 & 0.986 & 0.991 \\
\hline 0.5 & 0.813 & 0.851 & 0.894 & 0.975 & 0.980 & 0.986 \\
\hline 1.0 & 0.775 & 0.801 & 0.832 & 0.971 & 0.974 & 0.978 \\
\hline 2.0 & 0.770 & 0.780 & 0.795 & 0.970 & 0.971 & 0.973 \\
\hline
\end{tabular}

Table 2: Young's modulus reduction ratio for transversally cracked laminates [12].

Comparison of ECM-based predictions of the Young's modulus reduction with the crack density and experimental data for GFRP cross-ply laminates obtained by laser Raman spectroscopy [15] is shown in Fig. 4. A good agreement between the two is observed. 


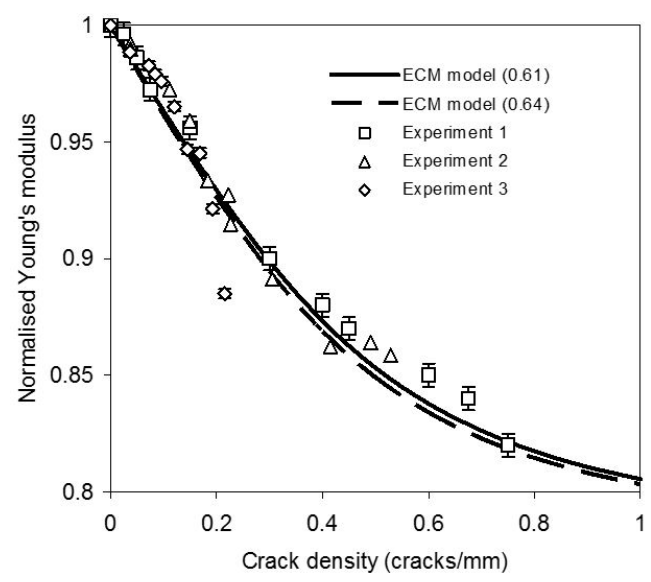

Figure 4: Normalized Young's modulus of a $\left[0^{\circ} / 90^{\circ}\right]_{\mathrm{s}}$ cross-ply laminate with cracked $90^{\circ}$ layer as a function of crack density [15].

\subsection{Post-buckling behaviour}

In this section, the analysis focuses on characteristic post-buckling responses and associated structurally stable or unstable behaviour. In Fig. 5, the post-buckling behaviour of delaminated matrix cracked cross-ply laminates is analysed in terms of normalized compressive load against normalized midpoint displacement. A laminate with the stacking sequence $\left[\left(0^{\circ} / 90^{\circ}\right)_{\mathrm{S}}\right]_{7}$ is exemplarily chosen. In order to provide an orientation about when damage growth occurs during post-buckling, deformation states causing delamination and matrix crack growth are indicated with the symbols $\square$ and $\bullet$ respectively. However, post-buckling responses are provided in Fig. 5 beyond these deformation states to account for the possibility of different material parameters (critical energy release rates) as well as enable a clear description of the post-buckling behaviour.

As can be seen in Fig. 5, depending on the delamination length and depth, the post-buckling behaviour can be categorized into four types, which can be described as follows:

- Type A: global, closed mode buckling with sublaminates getting in contact with each other after reaching a limit point ( $c f$. symbol $\diamond$ in Fig. 5),

- Type B: dominant global buckling with an initial closed mode response, which shifts to opening mode after reaching a limit point, 


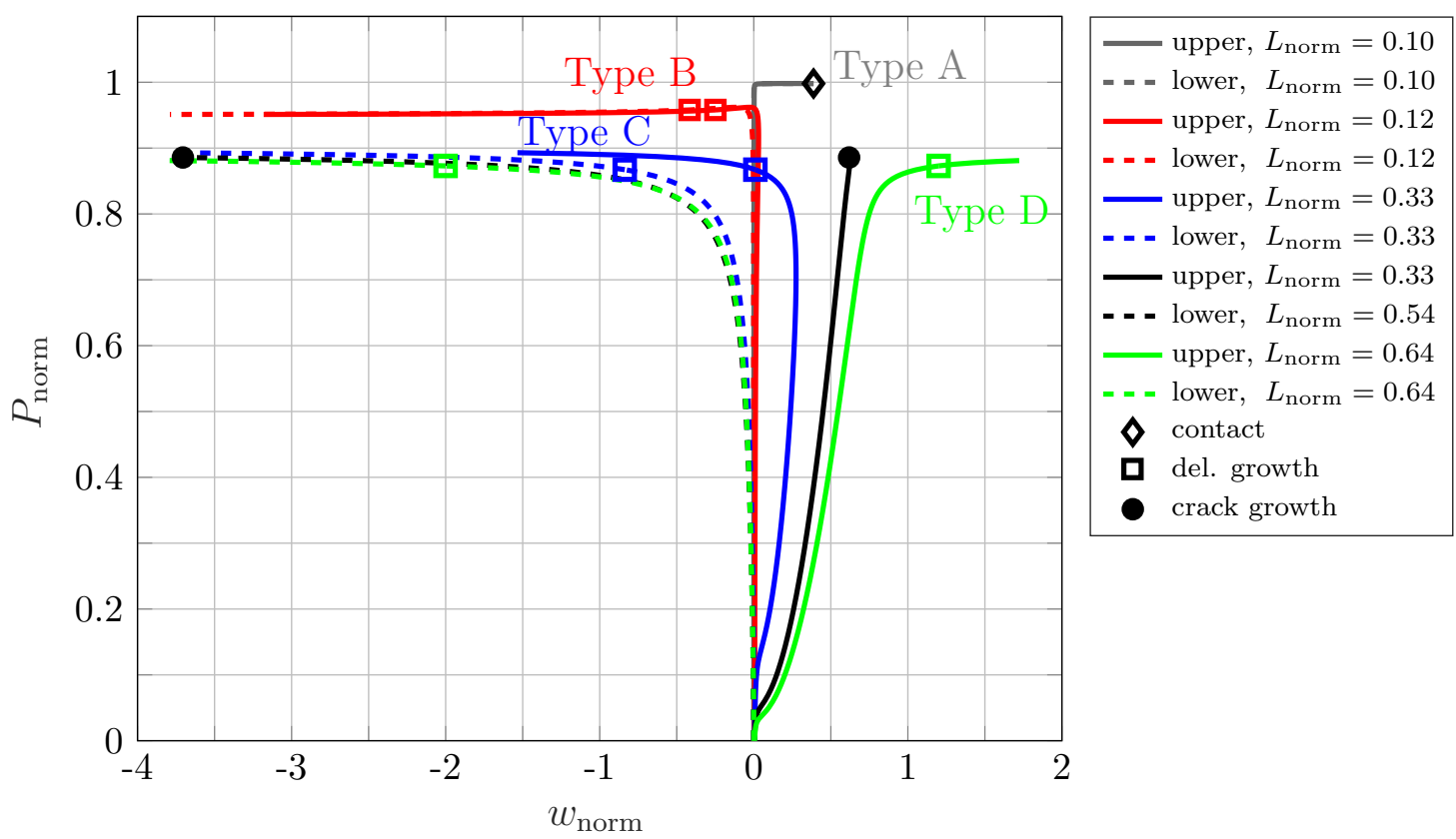

Figure 5: Post-buckling responses in terms of normalized compressive load $P_{\text {norm }}$ against normalized midpoint displacement $w_{\text {norm }}$; laminate: $\left[\left(0^{\circ} / 90^{\circ}\right)_{\mathrm{s}}\right]_{7}, a=3 / 28, L_{\text {norm }}=0.10-0.64$.

- Type C: local opening mode buckling response with ensuing dominant global response (no limit point),

- Type D: dominant local buckling with sublaminates deflecting in opposite direction throughout deformation (no limit point),

where the terminology of $[9,16]$ is used. It should be noted that the presence of matrix cracks plays a minor role regarding general post-buckling characteristics. Even though the maximum load observed during post-buckling responses decreases up to approximately $1.5 \%$ when comparing non-cracked laminates and laminates with a matrix crack density of $D=1.0$, the general characteristics remain barely affected. However, the lower stiffness of the cracked laminates yields that postbuckling types described occur at marginally larger delamination lengths (below $0.1 \%$ of $L_{\text {norm }}$ ) without altering the general findings.

Type A (cf. grey lines in Fig. $\left.5 ; L_{\text {norm }}=0.10\right)$ is characterized by a global buckling response, i.e. overall buckling of the strut. As described in [16], such type is associated with a closed mode buckling response, i.e. both sublaminates deflect 
in the same direction, where the system reaches a limit point [37], i.e. stability failure occurs in a load controlled configuration. Subsequently, the drop in load is associated with both sublaminates ( $c f$. Fig. 2: upper sublaminate (1), lower sublaminate (2)) getting in contact with each other from where the simulation is stopped.

Type B is illustrated in Fig. 5 for $L_{\text {norm }}=0.12$ (red lines), in which the deformation path also exhibits a limit point associated with the occurrence of global buckling. However, in this type of response, the drop in load goes along with a local buckling response, where the system is still dominated by global buckling (shift of both sublaminates in negative direction) but the sublaminates deflect in opposite directions with respect to each other, i.e. the distance between the sublaminates increases. Note that the sharpness of the limit point and therefore the drop in load depends on the depth of the delamination, which relates to the energy stored in the upper sublaminate. With smaller delamination depths, type A responses do not occur ( $c f$. Table A.1) and the limit point (type B) becomes barely detectable.

In type $\mathrm{C}$, the system exhibits initially a local buckling response, where the thinner, less stiff sublaminate buckles ( $c f$. solid blue line in Fig. $5 ; L_{\text {norm }}=0.33$ ). The local buckling response becomes more pronounced with increasing delamination length. The deformation path does not exhibit a limit point any more. With the occurrence of global buckling, the deformation path shows its characteristic behaviour where the load converges asymptotically towards its respective maximum load. This is associated with both sublaminates shifting into the negative direction. However, it should be noted that both sublaminates remain in an opening mode response.

Type D is characterized by a dominant local buckling response ( $c f$. green lines in Fig. $5 ; L_{\text {norm }}=0.64$ ). The less stiff sublaminate undergoes considerably larger buckling displacements then for smaller delamination lengths. As a consequence, with the occurrence of global buckling, the sublaminates remain shifting in opposite directions. Moreover, the transition into the global response is smoother compared with type $\mathrm{C}$, however, the maximum load decreases further with increasing delamination lengths. Note that in Fig. 5 , the case $L_{\text {norm }}=0.54$ (black lines) marks the transition from type $\mathrm{C}$ to type $\mathrm{D}$, which is in particular relevant regarding the 
damage growth behaviour that is discussed in detail in Section 3.3. Note that only for this case the active damage mechanism is matrix crack growth $(c f$. symbol $\bullet$ in Fig.5).

The post-buckling behaviour of delaminated cracked laminates is fully described by the aforementioned types A, B, C and D. The occurrence of the respective buckling type depends on the delamination length and delamination depth. In general, the deeper the delamination the larger the delamination lengths associated with the respective types (except for type D behaviour, $c f$. Fig. 6). The findings for the configurations studied are summarized in Fig. 6. The numerical data associated with Fig. 6 is provided in Table A.1 in Appendix A.

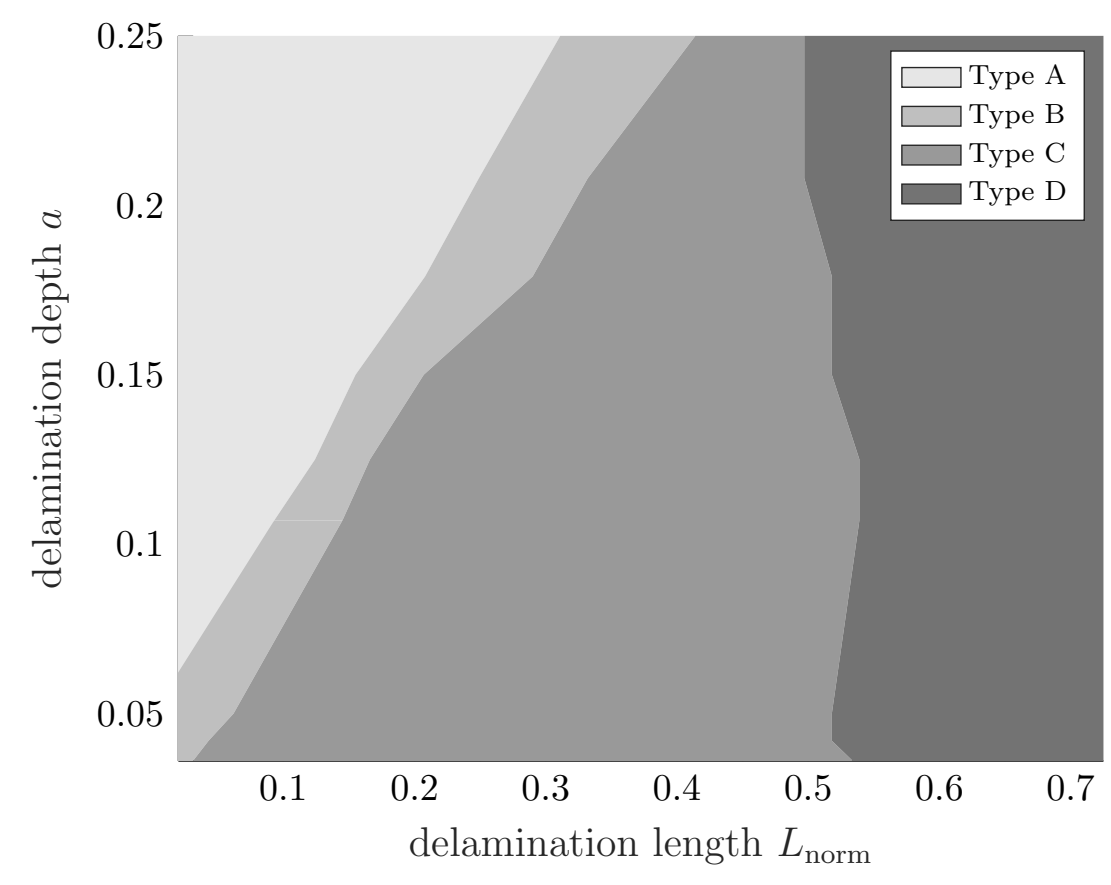

Figure 6: Map showing regions associated with post-buckling types A-D.

Fig. 6 provides a complete overview about the post-buckling behaviour of delaminated composite struts for delamination depth up to $a=0.25$. The following key findings can be taken from Fig. 6:

- The type of post-buckling response occurring depends on both delamination depth and length, where the span of delamination lengths associated with a respective post-buckling type alters with increasing delamination depth. 
- Delamination lengths associated with a transition in post-buckling types vary almost linearly with delamination depths.

- Regions associated with type $\mathrm{A}$ and type $\mathrm{C}$ responses behave inversely to each other with increasing delamination depth: Type $\mathrm{C}$ behaviour occurs for almost all delamination length (up to $L_{\text {norm }} \approx 0.50$ ) for shallow delaminations ( $a=1 / m, m$ - total number of plies in laminate) but is associated with smaller spans at larger delamination depths, whereas type A does not occur for shallow delaminations but is associated with larger spans of delaminations at lager depths.

- The transition from type $\mathrm{C}$ to type $\mathrm{D}$, thus the region associated with type $\mathrm{D}$ behaviour, is almost unaffected by changing delamination depth and occurs at $L_{\text {norm }} \approx 0.50-0.55$.

- The span of delamination length associated with type B responses remains similar with increasing delamination depths but shifts approximately linearly to larger delamination lengths.

- With deeper delaminations, the transition from dominant global buckling responses (types A and B) to post-buckling behaviour characterized by dominant local buckling (type D) occurs more abruptly.

The delamination lengths for which the post-buckling behaviour transitions from type $\mathrm{C}$ to $\mathrm{D}$ appears to be a characteristic configuration for the laminates studied. It determines the post-buckling response for which, with the occurrence of global buckling, the upper sublaminate remains in its position (midpoint deflection) and all deformation towards an increasing opening mode response is provided by the lower more stiff sublaminate owing to the global buckling response. This behaviour marks an important deformation characteristic of delaminated composite struts, which also affects the damage growth behaviour that is described next. 


\subsection{Damage growth behaviour}

The damage growth behaviour is described by analysing the behaviour of the energy release rates (ERR) for delamination and matrix crack growth against the applied end-shortening and the respective damage parameters (delamination length $L$ and matrix crack density $D$ ) for varying delamination depths.

\subsubsection{Delamination growth behaviour}

The behaviour of the ERR for delamination growth is analysed in general in Fig. 7, where relationships to the post-buckling characteristics described in Section 3.2 are drawn by indicating zones ( $c f$. vertical dotted lines in Fig. 7) which refer to post-buckling types A, B, C and D. As in Section 3.2, the cross-ply laminate with the stacking sequences $\left[\left(0^{\circ} / 90^{\circ}\right)_{\mathrm{s}}\right]_{7}$ and a delamination in between the third and fourth layer $(a=3 / 28)$ serves as an illustrative example.

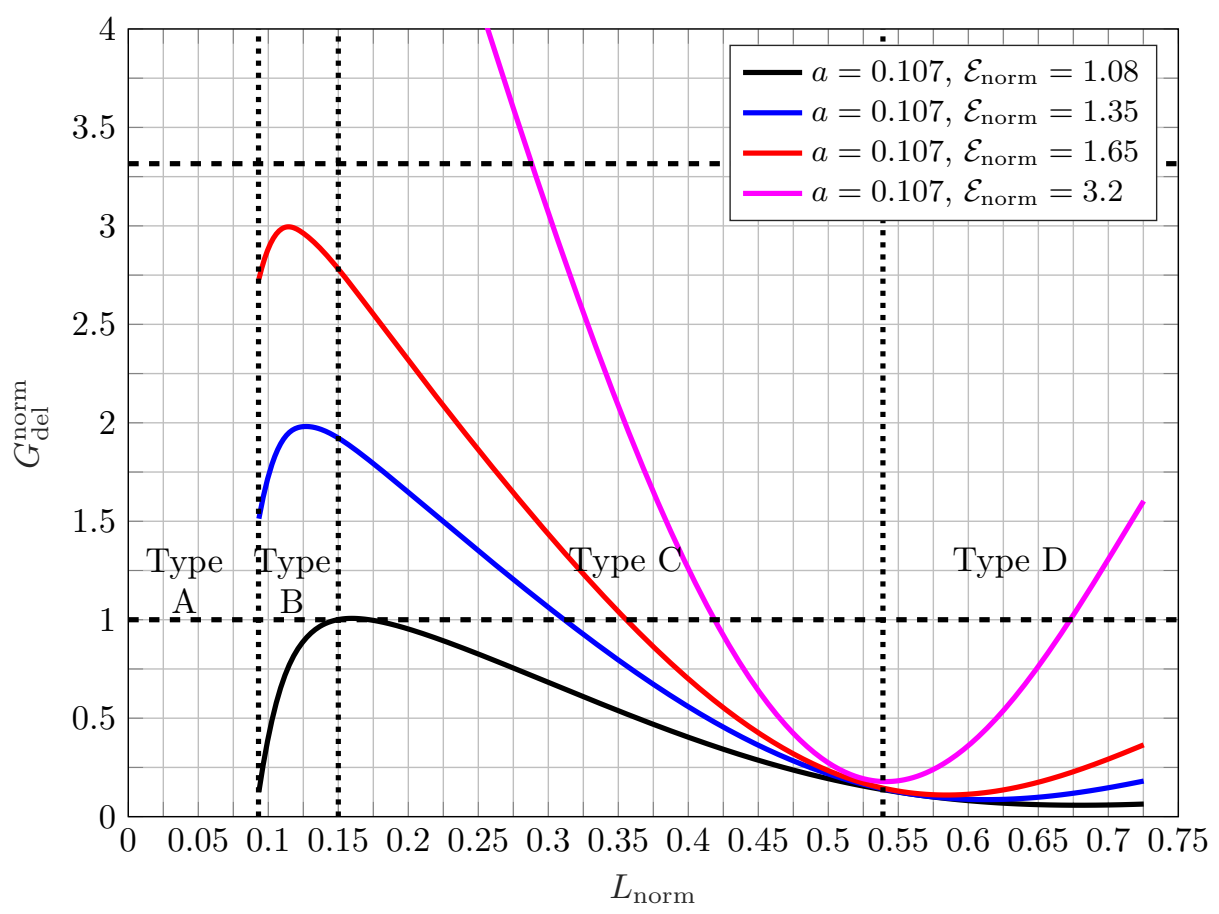

Figure 7: Behaviour of the energy release rate for delamination growth against delamination length for increasing applied end-shortening; zones Type A, Type B, Type C, Type D refer to the post-buckling behaviour identified; laminate: $\left[\left(0^{\circ} / 90^{\circ}\right)_{\mathrm{s}}\right]_{7}, a=3 / 28$; in normalized quantities.

In Fig. 7, the ERR for delamination growth $\left(G_{\text {del }}^{\text {norm }}\right)$ is shown against the delamination length $\left(L_{\text {norm }}\right)$ for increasing values of applied end-shortening $\left(\mathcal{E}_{\text {norm }}=\right.$ 
$\{1.08,1.35,1.65,3.20\})$. The energy release rate is normalized against the critical ERR of Mode I $\left(G_{\mathrm{c}}^{\mathrm{I}}=0.19 \mathrm{~N} / \mathrm{mm}\right)$, the end-shortening against the Euler buckling end-shortening of the intact strut and the delamination length against the total length. Assuming that $G_{\mathrm{c}}=G_{\mathrm{c}}^{\mathrm{I}}$, growth would be caused when the respective load level lines reach the horizontal dashed line at $G_{\text {norm }}=1$. A second horizontal dashed line is provided in Fig. 7 indicating the critical energy release rate of Mode II $\left(G_{\mathrm{c}}^{\mathrm{II}}=0.63 \mathrm{~N} / \mathrm{mm}\right)$.

Considering the regions associated with the types of post-buckling behaviour, it can be seen in Fig. 7 that delamination growth needs to be considered for post-buckling responses of types B, C and D. Owing to the closed mode buckling response, it has been expected that delamination growth does not constitute a relevant failure mechanism for type A configurations. ${ }^{5}$

It should be stressed that the regions associated with post-buckling types B, $\mathrm{C}$ and $\mathrm{D}$ also relate to characteristic points in the behaviour of the ERR, where type $\mathrm{B}$ is present for the initial increasing values of energy release rate $(c f$. Fig. 7, $0.09<L_{\text {norm }}<0.15$ ), type $\mathrm{C}$ ranges from the peak value for $\mathcal{E}_{\text {norm }}=1.08$ (black line) at around $L_{\text {norm }}=0.15$ to the vertex point developing for higher applied end-shortenings $\left(\mathcal{E}_{\text {norm }}=3.2\right.$, magenta line $)$ at $L_{\text {norm }}=0.54$. The vertex point describes a distinct minimum in the behaviour of the ERR, which remains below the threshold for delamination growth $\left(G_{\text {norm }}=1\right)$ for thin delaminations $(a \leq 0.125)$ and only vanishes for deeper delaminations ( $c f$. Fig. 10 in Appendix B) The vertex in the graph for $\mathcal{E}_{\text {norm }}=3.2$ also characterizes the transition to type D post-buckling which is associated with increasing values of the ERR.

These characteristic points also indicate changes in the delamination growth behaviour. Stable and unstable delamination growth is characterized by the change of the ERR with an increase in delamination length for a constant state of loading, i.e. whether the slope of the solid lines in Fig. 7 is positive (unstable) or negative (stable) $[4,18,20]$. Thus, assuming that growth would occur at $G_{\text {norm }}=1$, it follows from the black line $\left(\mathcal{E}_{\text {norm }}=1.08\right)$, that unstable delamination growth

\footnotetext{
${ }^{5}$ In type A, energy release rates associated with sliding mode II are present and increase with increasing distance of neutral axes of the sublaminate and intact strut. However, for the cases investigated in the current study $\left(L_{\text {tot }} / t>38.8\right.$, cf. Fig. 2$)$, such contributions are negligible before contact of the sublaminates occurs.
} 
occurs in the zone visualizing type B. Stable delamination growth is present in the zone associated with type $\mathrm{C}$ and unstable delamination growth would be caused in the zone of type D. It should be noted that for type B and C the same qualitative behaviour (unstable - type B; stable - type C) is given for structural stability and damage growth behaviour, whereas in zone type D structurally stable behaviour is associated with unstable delamination growth. In an analogues manner, the delamination growth behaviour can be evaluated for a force-controlled system, which is provided in Appendix $\mathrm{C}$ plotting the energy release rate for increasing magnitudes of compressive force.

The analysis performed for the configurations studied in Fig. 7, has been conducted for all nine delamination depths. The corresponding graphs are provided in Appendix A. The detailed information about the behaviour of the ERR for delamination growth is subsequently summarized by mapping configurations associated with stable and unstable delamination growth against delamination depth and length. This relationship is visualized in Fig. 8.

Note that configurations associated with stable and unstable delamination growth depend, apart from delamination depth and length, also on the total thickness of the laminates. Owing to the effect of laminate thickness (thus also lower sublaminate thickness) on the ERR, i.e. energy released in the intact part and the lower sublaminate), the results are not presented in a completely generalized manner, as it has been done for the post-buckling behaviour in Section 3.2. In Fig. 8, the regions associated with stable and unstable behaviour are presented for each laminates studied: $\left[\left(0^{\circ} / 90^{\circ}\right)_{\mathrm{s}}\right]_{n}$, with $n=\{7,6,5\}$, in Figs. 8 a to $8 \mathrm{c}$, respectively.

In Fig. 8, regions exhibiting stable delamination growth behaviour are visualized by light grey shaded areas and unstable behaviour by dark grey shaded areas. Configurations where contact of both sublaminates occurs before the ERR reaches its critical value are highlighted by the symbol *. Similarities in comparison with the map highlighting all types of post-buckling behaviour ( $c f$. Fig. 6) are apparent. The region indicating contact corresponds directly to type A post-buckling responses. Further, in Figs. 8a and 8b, a linearly shifting band of unstable configurations is present which relates to regions exhibiting type B post-buckling behaviour. The large light grey area in Figs. 8a to 8c, indicating stable delamination growth, is mostly associated with type $\mathrm{C}$ post-buckling responses. Moreover, the transition 


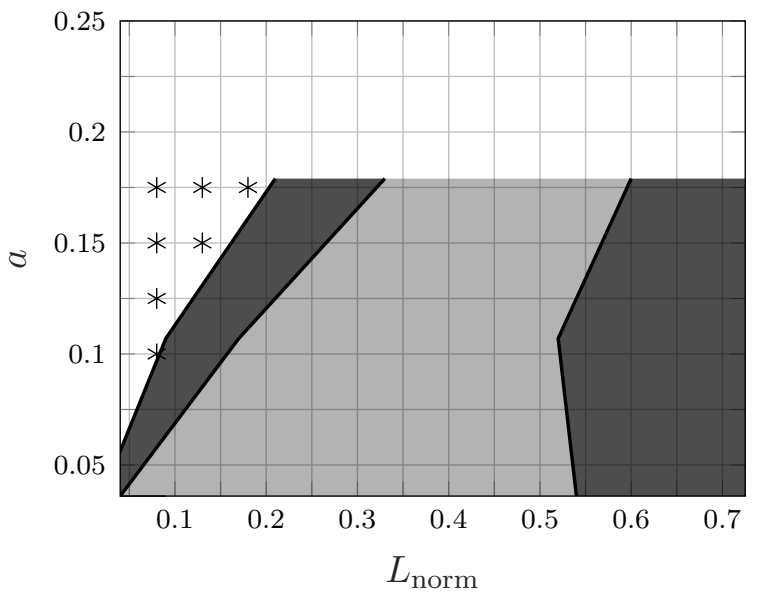

(a) laminate $\left[\left(0^{\circ} / 90^{\circ}\right)_{\mathrm{s}}\right]_{7}, n=7$

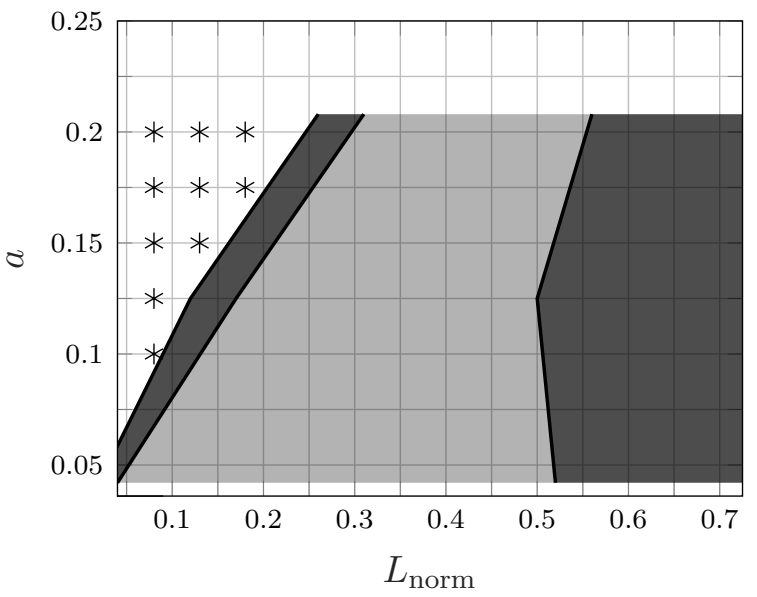

(b) laminate $\left[\left(0^{\circ} / 90^{\circ}\right)_{\mathrm{s}}\right]_{6}, n=6$
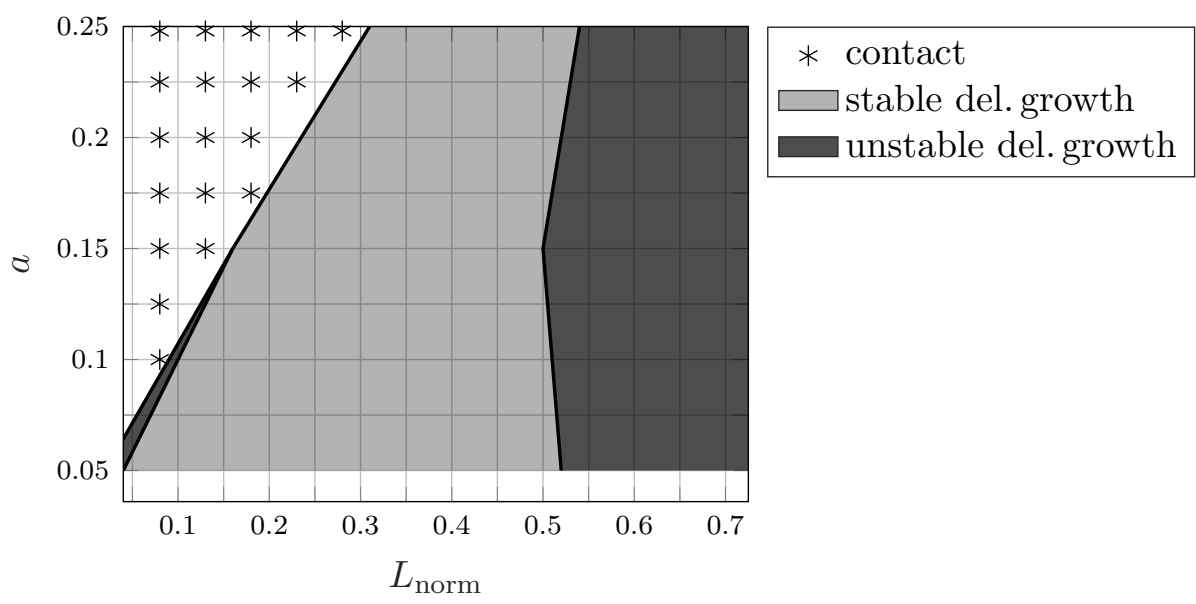

(c) laminate $\left[\left(0^{\circ} / 90^{\circ}\right)_{\mathrm{s}}\right]_{5}, n=5$

Figure 8: Maps showing regions associated with stable and unstable delamination growth for the laminates $\left[\left(0^{\circ} / 90^{\circ}\right)_{\mathrm{s}}\right]_{n}$, with $n=\{7,6,5\}$.

from stable to unstable delamination growth occurs in a similar region as the transition from post-buckling type C to D.

Apart from the aforementioned similarity to the post-buckling behaviour, Fig. 8 visualizes the effect of delamination depth and laminate thickness. Note that the total amount of layers $(m)$ decreases from Fig. $8 \mathrm{a}(m=28)$ to Fig. $8 \mathrm{c}(m=$ 20). Increasing delamination depth yields smaller spans of delamination lengths associated with stable delamination growth, i.e. decreasing light grey area in 8 . Increasing laminate thickness does not alter this general finding but affects the 
extent of each region shown in the maps. First, with increasing laminate thickness, a region develops at the transition from configurations showing contact, which exhibits unstable delamination growth and is mainly associated with type B postbuckling. This regions increases with larger delamination depth and laminate thickness. Further, the effect of delamination depth on the transition from stable to unstable delamination growth becomes more relevant for larger laminate thicknesses (cf. delamination lengths $L_{\text {norm }} \approx 0.5-0.6$ in Figs. 8a and $8 \mathrm{c}$ ) shifting unstable configurations to larger delamination lengths.

\subsubsection{Matrix crack growth behaviour}

The damage growth behaviour of matrix cracks present in the laminate is studied in this section. Therefore, Fig. 9 shows the energy release rate for matrix crack growth against the matrix crack density for certain given delamination lengths $\left(L_{\text {norm }}=\{0.58,0.60,0.62\}\right)$ and increasing levels of load input $\left(\mathcal{E}_{\text {norm }}\right)$. The energy release rate for matrix crack growth $G_{\mathrm{mc}}$ is normalized to the critical mode I energy release rate. The laminate $\left[\left(0^{\circ} / 90^{\circ}\right)_{\mathrm{s}}\right]_{7}$ with a delamination depth of $a=1 / 28$ serves as an illustrative example.

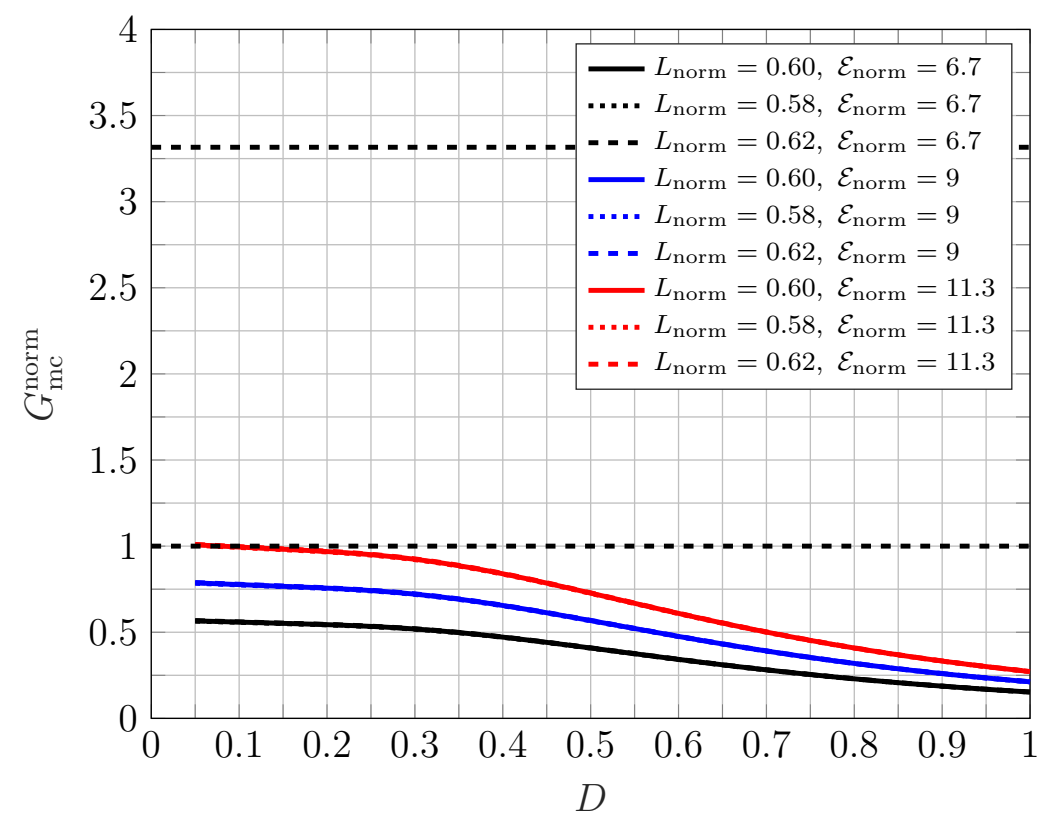

Figure 9: Normalized energy release rate $v s$. matrix crack density for $L_{\text {norm }}=\{0.58,0.60,0.62\}$ for increasing load input $\mathcal{E}_{\text {norm }}$; laminate: $\left[\left(0^{\circ} / 90^{\circ}\right)_{\mathrm{s}}\right]_{7}, a=1 / 28$. 
For small matrix crack densities up to $D=0.20-0.25$, the energy release rate shows a plateau-like behaviour with slightly decreasing magnitudes. In the cases presented in Fig. $9\left(L_{\text {norm }}=\{0.58,0.60,0.62\}\right)$, matrix crack growth is caused for an end-shortening of $\mathcal{E}_{\text {norm }}=11.3$ for matrix crack densities $D=0.05-0.15$, where increasing delamination length marginally affects the energy release rate for matrix crack growth ( $c f$. dotted, solid and dashed lines in $c f$. Fig. 9). Throughout the range of matrix crack densities studied, the energy release rate decreases with increasing matrix crack densities for constant levels of load input. Thus, any matrix crack growth initiated would be stable. However, it remains to be clarified which damage mechanism is dominant for the configurations studied and whether interactions between both may occur. Therefore, Fig. 10 shows the energy release rates for delamination growth and matrix crack growth against both damage parameters. As in Fig. 9, the laminate $\left[\left(0^{\circ} / 90^{\circ}\right)_{\mathrm{s}}\right]_{7}$ with $a=1 / 28$ is analysed, however the delamination lengths considered in Figs. $10 \mathrm{~b}$ and $10 \mathrm{~d}$ are $L_{\text {norm }}=\{0.41,0.44,0.46\}$.

Since Fig. 10a shows the behaviour of the energy release rate for delamination growth against delamination length for larger magnitudes of applied end-shortening $\left(\mathcal{E}_{\text {norm }}=\{6.6,9.0,11.4\}\right)$ than in Fig. 7 , the aforementioned distinct minimum present for thin-film delaminations at around $L_{\text {norm }} \approx 0.5$ is clearly visible. The span of delamination lengths $\left(L_{\text {norm }}=0.43-0.60\right)$ around the minimum value where the the energy release rate for delamination growth remains below its critical value defines the region for which matrix crack growth becomes the dominant failure mechanism. This is underlined by Figs. 10c and 10d showing the energy release rate for matrix crack growth against delamination length and crack density respectively. As can be seen in Fig. 10c, in the region of $L_{\text {norm }}=0.43-0.60$, the energy release rate for matrix crack growth remains almost constant at $G_{\mathrm{mc}}^{\mathrm{norm}}=1$ with slightly increasing values towards larger delamination lengths. Larger matrix crack densities $(D=\{0.1,0.2,0.3\})$ cause slightly lower energy release rates ( $c f$. dashed, solid and dotted lines in Fig. 10c). The decrease in energy release rate with larger crack densities is described in Fig. 10d showing the aforementioned plateau-like behaviour up to $D=0.25$ from where the energy release rate gradually declines towards a crack density of $D=1.0$.

Summarizing the information provided in Fig. 10, it can be stated that, for the 


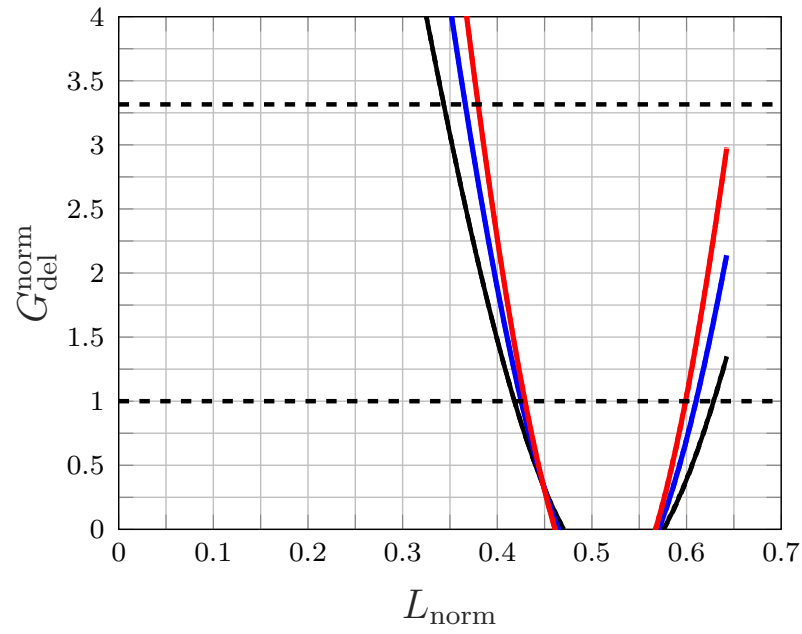

(a) $G_{\text {del }}^{\text {norm }}$ vs. $L_{\text {norm }}$

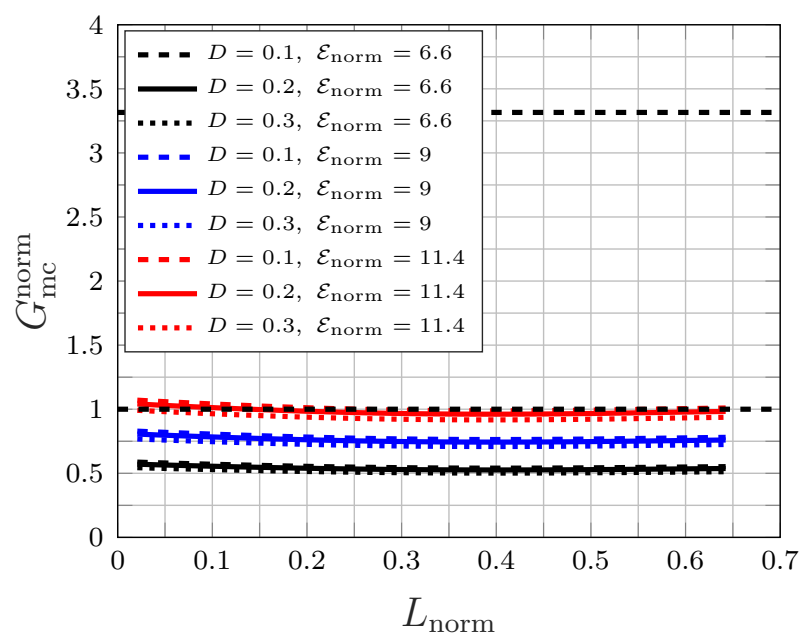

(c) $G_{\mathrm{mc}}^{\text {norm }}$ vs. $L_{\text {norm }}$

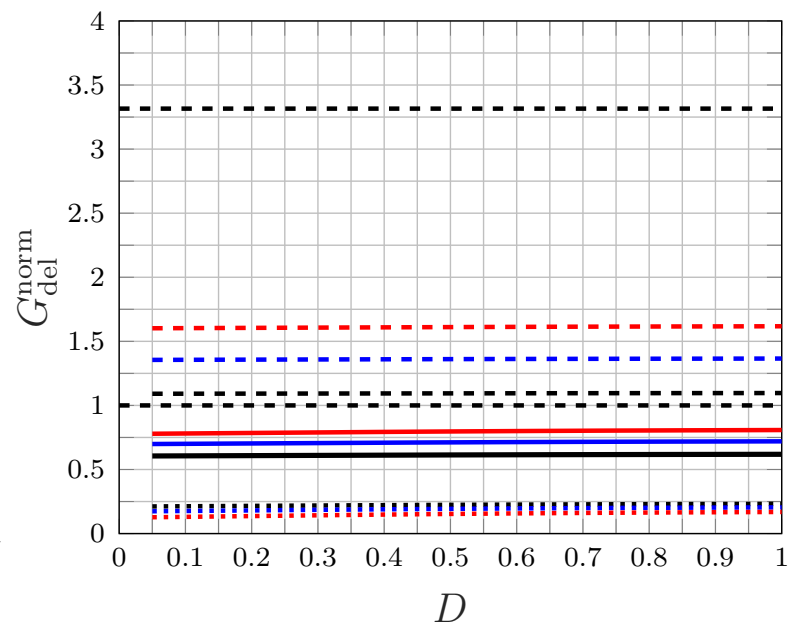

(b) $G_{\text {del }}^{\text {norm }}$ vs. $D$

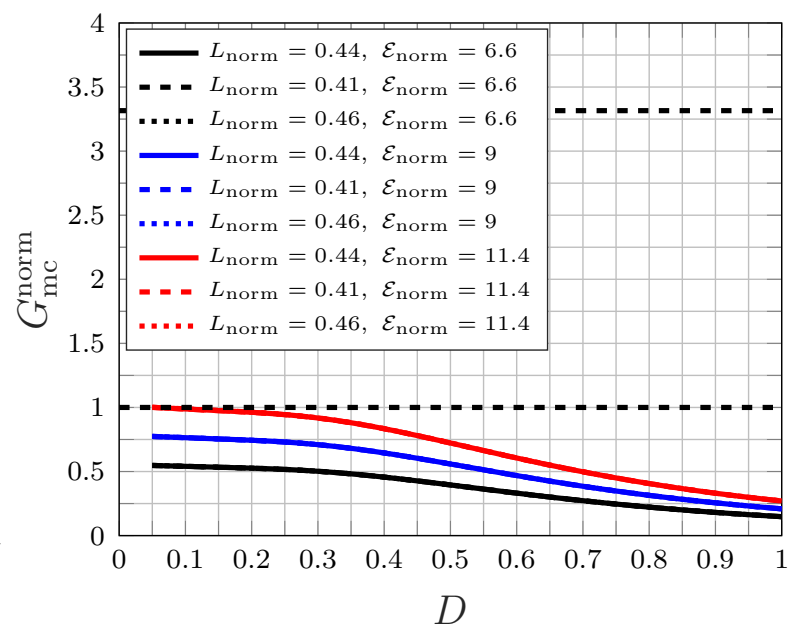

(d) $G_{\mathrm{mc}}^{\text {norm }}$ vs. $D$

Figure 10: Normalized energy release rates $\left(G_{\text {del }}^{\text {norm }}, G_{\mathrm{mc}}^{\text {norm }}\right)$ against the damage parameters $\left(L_{\text {norm }}\right.$, $D)$ for increasing levels of load input (normalized end-shortening $\left.\mathcal{E}_{\text {norm }}\right)$, laminate: $\left[\left(0^{\circ} / 90^{\circ}\right)_{\mathrm{s}}\right]_{7}$.

laminate studied, outside the region identified $\left(L_{\text {norm }}=0.43-0.60\right)$ delamination growth is the dominant failure mechanism, whereas inside the region matrix crack growth is present. Thus, there are two configurations (lower limit and upper limit of $\left.L_{\text {norm }}=0.43-0.60\right)$ which will be prone to interactions of both failure mechanisms. The damage growth behaviour once both mechanisms are triggered can be analysed with the aid of Figs. 10b and 10c. Both figures indicate that in the region of interest (lower limit: $L_{\text {norm }}=0.43$, upper limit: $L_{\text {norm }}=0.60$ ) the energy release 
rate for one of the damage mechanism will increase with a change in the other damage parameter. On the other hand, for the lower limit, the energy release rate for delamination length and matrix crack growth decrease with an increase the their respective damage parameter. Thus, the deviations caused by the changes in the respective damage parameters will govern whether growth would be stable or unstable, where the significant decline in energy release rate for delamination growth dominants the behaviour related with delamination growth and the slope of both Figs. 10c and 10d indicate that matrix crack growth will also follow a stable regime, i.e. the energy release rate for matrix crack growth decreases for small increases $\Delta L_{\text {norm }}$ and $\Delta D$. The opposite in given when analysing the upper limit $\left(L_{\text {norm }}=0.63\right)$, where the significant increase in energy release rate for delamination growth will govern the response of the structure and cause failure due to unstable delamination growth.

Outside of the identified region, the energy release rate for delamination growth strongly increases and reaches magnitudes larger than the critical energy release rate of mode II at $L_{\text {norm }} \approx 0.39$ and $L_{\text {norm }} \approx 0.67$. Thus, the maximum span of the region prone to matrix crack growth as well as failure mechanisms interaction is $0.39<L_{\text {norm }}<0.67$ when delamination growth would be governed by pure mode II, i.e. $G_{\mathrm{c}}=G_{\mathrm{c}}^{\mathrm{II}}$. The region in which matrix crack growth is the dominant failure mechanism decreases and eventually vanishes with increasing delamination depth $a$ ( $c f$. dotted lines in Fig. B.1 in Appendix B). For delamination depths $a=3 / m$, a region of $0.46<L_{\text {norm }}<0.57$ has been observed where the upper boundary further decreases to $L_{\text {norm }} \approx 0.54$ for delamination depths $a=0.150$. Moreover, the end-shortening required to cause the energy release rate for matrix crack growth to reach its critical value increases significantly. For delamination depth $a=5 / \mathrm{m}$, delamination growth is the sole active damage mechanisms.

\subsubsection{Load predictions for damage growth}

Apart from understanding the post-buckling and damage growth behaviour, information about loads causing damage growth is essential in a designing process. Therefore, the applied end-shortening $\left(\mathcal{E}_{\text {norm }}^{\text {dam }}\right)$ and the associated compressive force $\left(P_{\text {norm }}^{\text {dam }}\right)$ causing damage growth are shown in Figs. 11a and 11b respectively. Note that normalization is still performed against the respective Euler load. 


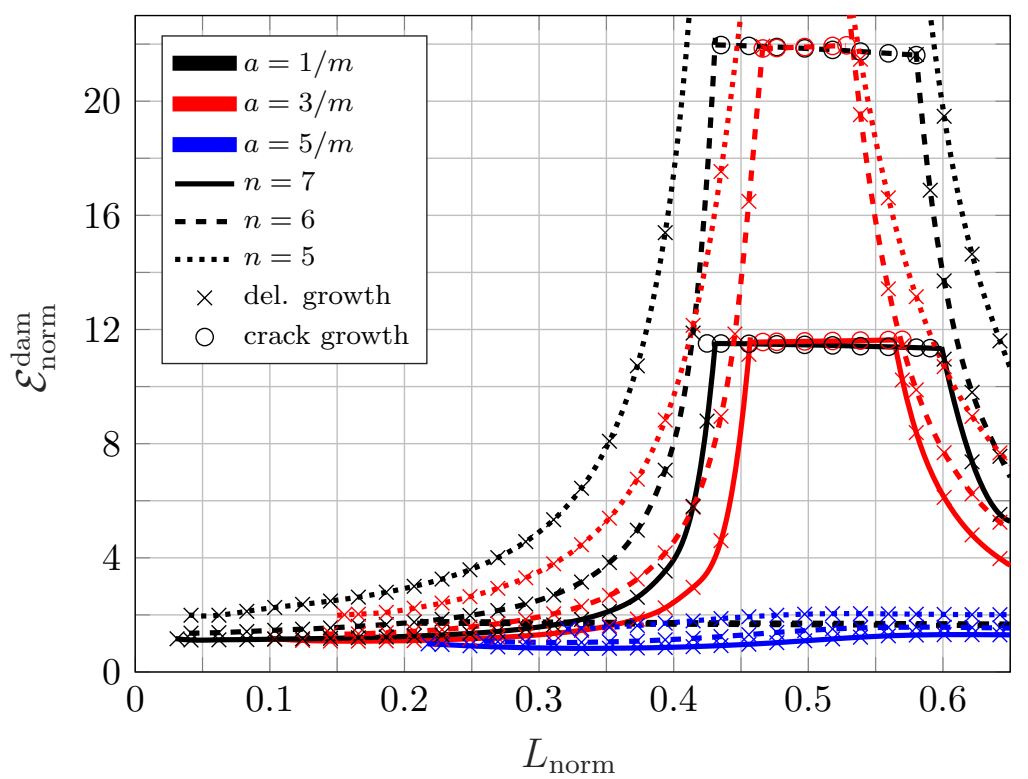

(a) $\mathcal{E}_{\text {norm }}^{\text {dam }}$ vs. $L_{\text {norm }}$ for all depths $a$.

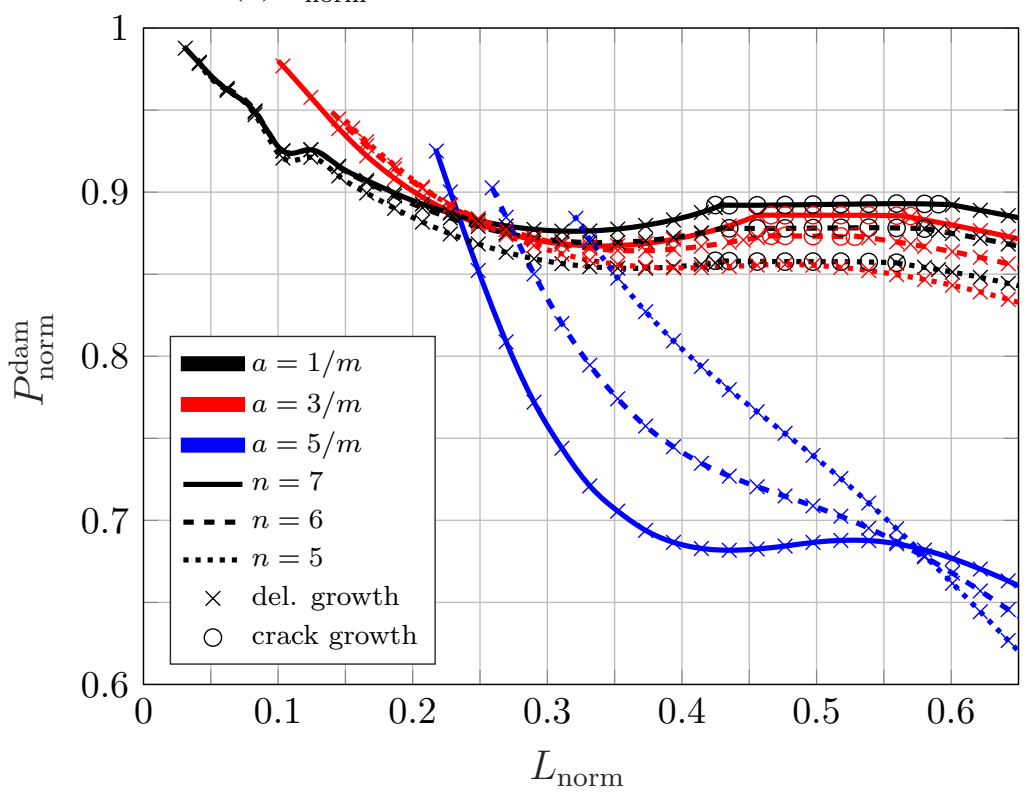

(b) $P_{\text {norm }}^{\text {dam }}$ vs. $L_{\text {norm }}$ for all depths $a$.

Figure 11: (a) Applied end-shortening causing damage growth $\left(\mathcal{E}_{\text {norm }}^{\text {dam }}\right)$ against delamination length $\left(L_{\text {norm }}\right)$ and depth $(a)$; (b) compressive force causing damage growth $\left(P_{\text {norm }}^{\text {dam }}\right)$ against delamination length $\left(L_{\text {norm }}\right)$ and depth $(a)$; laminates $\left[\left(0^{\circ} / 90^{\circ}\right)_{\mathrm{s}}\right]_{n}, n=\{7,6,5\}, m$ - total number of layers.

In Fig. 11, for the laminate studied: $\left[\left(0^{\circ} / 90^{\circ}\right)_{\mathrm{s}}\right]_{n}$ (with $\left.n=\{7,6,5\}\right)$, all configurations relating with delaminations in between the first and the second layer, 
i.e. $a=1 / m$ with $m$ being the total number of layers, are visualized in black; cases for $a=3 / m$ in red and $a=5 / m$ in blue. Reference to the specific laminate and configuration is then provided by solid $(n=7)$, dashed $(n=6)$ and dotted $(n=5)$ lines (e.g. the dashed black line refers to laminate $\left[\left(0^{\circ} / 90^{\circ}\right)_{\mathrm{s}}\right]_{6}$ with a delamination in between the first and second layer; $a=1 / m$ ). Further, configurations associated with delamination growth and matrix crack growth are marked by the symbols $x$ and $\circ$ respectively.

Key findings provided in Fig. 11 are:

- For delamination depths $a=\{1 / m, 3 / m\}$, a characteristic region around delamination lengths $L_{\text {norm }} \approx 0.42-0.60$ can be identified where significantly more applied end-shortening is required to cause damage growth. As discussed in Section 3.3.2, in this region matrix crack growth (symbols o) occurs before delamination growth. The largest span of delamination lengths prone to matrix crack growth is given for thick laminates with thin delaminations (black solid and dashed line), which decreases with deeper delaminations and thinner laminates (red lines) and vanishes for the case $a=3 / m$ and $n=5$ (red dotted line).

- It should be stressed that this region can also be identified looking at compressive forces causing damage growth $\left(P_{\text {norm }}^{\text {dam }}\right)$. For $a=\{1 / m, 3 / m\}$, these forces are close to the buckling load of the intact laminates $\left(P_{\text {norm }}^{\text {dam }}=1\right)$ for small delamination lengths and decrease subsequently with larger lengths up to $P_{\text {norm }}^{\text {dam }} \approx 0.85-0.87$ at $L_{\text {norm }} \approx 0.30-0.35$, which describes a local minimum in the response of the forces in Fig. 11b. A slight increase in compressive force is present for larger delamination length leading to the region associated with matrix crack growth, which resembles a plateau-like local maximum.

- A changeover in the response is given for deeper delaminations $(a=5 / m$, blue lines), where the region associated with matrix crack growth is not present any more, thus delamination growth is the dominant failure mechanism for all configurations, and significantly smaller end-shortenings are required to cause delamination growth. For thicker laminates, delamination growth may occur already at $\mathcal{E}_{\text {norm }}^{\text {dam }}<1$ and the maximum end-shortening causing growth is around $\mathcal{E}_{\text {norm }}^{\text {dam }}=2$. 
- Except of the smallest delamination lengths, the compressive forces causing delamination growth are also smaller than for $a=\{1 / m, 3 / m\}$, where larger delamination lengths yield a stronger decrease in the forces associated with delamination growth. This relates to delamination growth occurring with or before global buckling.

- For deeper delaminations (blue lines), thicker laminates (solid line) exhibit delamination growth at considerably smaller compressive forces up to delamination lengths that relate to the transition from post-buckling type $\mathrm{C}$ to $\mathrm{D}$ as well as stable to unstable delamination growth $\left(L_{\text {norm }} \approx 0.55-0.60\right)$.

- It should be stressed that for all cases except of the red and blue dotted lines $\left(\left[\left(0^{\circ} / 90^{\circ}\right)_{\mathrm{s}}\right]_{5}, a=\{3 / m, 5 / m\}\right)$, the initial part of each curve is associated with unstable delamination growth (cf. Fig. 8).

\section{Discussion}

The results presented in Section 3 provide detailed information about

- the structural stability behaviour,

- the damage growth behaviour as well as

- the interaction of stability and damage growth behaviour

of delaminated, matrix cracked cross-ply laminates. The structural stability behaviour is dominated by delamination buckling, where matrix cracks only play a minor role causing a small reduction in characteristic loads (buckling and maximum loads) owing to reductions in stiffness of the respective part of the strut.

The comprehensive analysis of the structural stability behaviour in Section 3.2 constitutes a generalisation of the work documented in [9] and [21], where isotropic material behaviour and a fixed delamination depth had been considered respectively, in order to classify post-buckling responses. In the current work, it has been shown that four characteristic buckling responses can been identified ( $c f$. Table A.1: types A, B, C, D), where each type is associated with respective ranges of delamination depth and length. Although not specifically categorized, such postbuckling responses (except of type D) are also described in [9] with the aid of 
exemplary cases for which load vs. end-shortening information is provided. Besides considering a layered structure with unidirectional plies exhibiting transversely isotropic material behaviour, the current study, owing to the extensive parametric study, determined precise ranges for which each post-buckling type occurs. As a consequence, it has been shown that both quantities delamination length and depths are required to determine the type of post-buckling response, thus the extent of each region associated with respective types of post-buckling. For the cases considered (cross-ply laminates, delamination depth $a \leq 0.25$ ), the information provided in Fig. 6 and Table A.1 completes the study of the post-buckling behaviour of delaminated cross-ply laminates.

It can further be argued that, for the structure investigated, i.e. composite strut with a through-the-width delamination, where the width of the strut is considerably smaller than the length, the qualitative behaviour (types of responses) will not be affected by other stacking sequences. However, it can be expected, owing to the change in stiffness of the respective sublaminates, that the regions identified in Fig. 6 and Table A.1 will change quantitatively (cf. [21]).

Regarding delamination growth, it is of special importance to identify configurations which cause a changeover in the buckling response from closed mode to opening mode responses. Opening mode responses are prone to delamination growth owing to the tearing mode fracture behaviour, which occurs when both sublaminates deflect in opposite directions. These configurations have been determined and visualized in Fig. B.1 indicating the transition from type A to type B post-buckling behaviour. Employing the terminology introduced in [3], the delamination depth at which the aforementioned transition occurs is termed as critical delamination depth $a_{\text {crit }}$, providing a measure for which configurations delamination growth is a relevant failure mechanism.

Considering the structural stability behaviour, it should be stressed that all configurations referring to the measure critical depth exhibit structurally unstable behaviour, which has been characterized as type B post-buckling behaviour in Fig. B.1. Note that type B responses undergo opening mode deformations following the limit point from where both sublaminates deflect in the same direction, however 
with increasing out-of-plane displacements relative to each other. ${ }^{6}$ Owing to the relatively sharp limit point characteristics, type B responses appear to be most dangerous in relation to structural stability. Further, as presented in Section 3.3, with the exception of delamination depth $a=\{3 / 20,5 / 20\}$ for laminate $\left[\left(0^{\circ} / 90^{\circ}\right)_{\mathrm{s}}\right]_{5}$, type B post-buckling responses are also associated with unstable delamination growth. Thus, the region exhibiting type B post-buckling behaviour ( $c f$. Fig. B.1) constitutes worst case scenarios for possible delamination in cross-ply laminates.

As for type B post-buckling responses, relationships can be drawn in between stable delamination growth and type $\mathrm{C}$ post-buckling responses as well as unstable delamination growth and type D behaviour ( $c f$. Tables A.1 and B.1). It should be recalled ( $c f$. Fig. 5) that type $\mathrm{C}$ behaviour, although exhibiting an openingmode buckling response, is characterized by dominant global buckling, where both sublaminates shift into the same direction. Thus, the opening tearing fracture mode can be understood as in a certain extent contained, which can be regarded as controlled by the dominant global buckling. This containment is not present in type $\mathrm{D}$ responses where both sublaminates deflect in opposite direction, thus providing an active contribution towards the tearing fracture mode. Therefore, slightly larger delamination lengths are related with the transition from stable to unstable delamination growth than for the transition from type $\mathrm{C}$ post-buckling responses to type D. Since at the transition from type $\mathrm{C}$ to type $\mathrm{D}$ behaviour the upper sublaminate remains in its positions ( $c f$. green solid line in Fig. 5) and opening mode contributions are solely provided from global buckling, the energy release rate exhibits its characteristic minimum value as described in Section 3.3.

Such characteristic behaviour for delaminated composite struts causes matrix crack growth to become relevant in the region around the transition of type $\mathrm{C}$ to type $\mathrm{D}$, i.e. around the distinct minimum of energy release rate for delamination growth. As shown in Section 3.3.2, this region can maximally span to $0.39<L_{\text {norm }}<0.67$, which underlines the importance of considering matrix crack growth. The presence of matrix crack growth, in particular since exhibiting a stable growth behaviour, may be regarded as harmless, since it would only yield minor reductions in stiffness and thus loads bearable by the strut, however, minor changes in stiffness may lead to shifts in regions associated with post-buckling responses and thus changes to when

\footnotetext{
${ }^{6} \mathrm{In}[9]$, this type of response is referred to as mixed-mode response.
} 
stable or unstable delamination growth occurs. In addition, considering fatigue loading neglecting the information provided in Section 3.3 may result in missing out an accumulation of matrix cracks in outer layers. The results have also shown that there is a possibility of interaction between delamination growth and matrix crack growth. However, for the cases investigated, delamination growth dominates the structure's response causing stable or unstable delamination growth, whenever interaction between matrix crack and delamination growth occurs. Moreover, it has been observed that matrix cracks growth is only relevant when the cracked layers are on the outer opposite site of the delamination.

With the results presented in Sections 3.2 and 3.3, the study provides a detailed analysis of the relationship between post-buckling and damage growth behaviour. This is enabled by the analytical modelling approach comprising only four generalized coordinates, so that comprehensive parametric studies can be performed. It should be noted that the analysis does not consider certain deformation characteristics, such as out-of-plane shear deformations and in-plane non-constant strains. The former is regarded as expedient since only minor quantitative deviations may be expected owing to the thin laminates considered in the study (length/thickness $\approx 39-54$ ). If required or deemed necessary, then significantly more generalized coordinates as part of approximative functions of the rotation of the cross section have to be introduced to the modelling approach in Section 2.2 (cf. [29]). An approximative series of the in-plane displacement field would be required to consider mode mixture in the delamination growth behaviour [17]. In contrast, changes to the post-buckling behaviour would be negligible, owing to the strut exhibiting almost no compressive stiffness once buckled [37]. Apart from that, since the delamination growth direction is specified by the problem (through-the-width delaminations), the mode I assumption employed in the study provides truly conservative predictions. Beyond that, the objective of the study has been to analyse the relationship between post-buckling and damage growth behaviour, where mode mixture would cause the critical threshold to be somewhere in between the horizontal dashed lines in Figs. 7 ( $c f$. also Fig. B.1 in Appendix Appendix B) and thus only yield quantitative changes to the results summarized in Tables A.1 and B.1. Such deviations could be directly extracted from Figs. B.1a to B.1c. 


\section{Conclusions}

With the aid of an analytical modelling approach, comprising

- an energy formalism based on the total potential energy principle to determine post-buckling responses and energy release rates for delamination and matrix crack growth, as well as

- the Equivalent Constrained Model for deriving reduced stiffness quantities depending on given matrix crack densities,

the compressive behaviour of delaminated, matrix cracked cross-ply laminates has been analysed in detail. The study provides insight into the relationship of post-buckling and damage growth behaviour, which so far has often been treated separately or in a less generic way. As a consequence, stable and unstable delamination growth behaviour could be directly associated with characteristic postbuckling responses, which constitutes an important step towards understanding in detail the compressive behaviour of delaminated composite structures. Besides that, the work investigated whether matrix crack growth would be a relevant damage mechanism when studying delamination buckling. Owing to the analysis of all three behaviours: post-buckling, delamination, matrix crack; configurations of delaminated, matrix cracked composite struts have been identified for which matrix crack growth is the dominant failure mechanism.

The modelling approach employs four generalized coordinates only and thus constitutes an efficient analysis tool for delamination buckling of matrix cracked composite struts. Owing to the small number of unknowns employed, certain deformation characteristics, e.g. out-of-plane shear, are not considered in the modelling approach. However, as discussed in Section 4, this is not expected to alter the qualitative behaviour and would only cause minor quantitative changes to the findings provided in Section 3. The model can also be considered as an approach to add multiple active damage mechanisms to the analysis of the compressive behaviour of damaged composite structures, which besides multiple delaminations (e.g. $[8,24])$ has not been done in analytical modelling approaches.

In summary, owing to an extensive parametric study, a comprehensive analysis of the post-buckling behaviour, delamination growth behaviour and matrix crack 
growth behaviour has been conducted for cross-ply laminates loaded under in-plane compression. Beyond that, the analysis enabled to draw relationships between postbuckling and damage growth, in particular delamination growth, behaviour, which helps to better understand the compressive behaviour of delaminated composite structures. Moreover, the detailed characterization and identification of regions associated with types of post-buckling behaviour as well as stable and unstable delamination growth behaviour highlights scenarios which prove most dangerous regarding failure of the structure that serves towards designing safer structures.

\section{Appendix A. Overview of the post-buckling behaviour}

The numerical results of the study of the post-buckling behaviour presented in Section 3.2 are summarized Table A.1. With the results shown, the four regions of post-buckling behaviour (type A-D) are visualized in Fig. 6. The delamination depth is denoted by parameter a describing the thickness of the upper sublaminate in relation to the total thickness of the strut ( $c f$. Fig. 5), where $m$ is the total amount of plies in the laminates with the stacking sequence $\left[\left(0^{\circ} / 90^{\circ}\right)_{\mathrm{s}}\right]_{n}(n=\{5,6,7\})$.

\begin{tabular}{c|c|c|c|c|c}
\multirow{2}{*}{$\begin{array}{c}\text { depth } a \\
m=\{28,24,20\}\end{array}$} & type A & type B & type C & type D \\
\cline { 3 - 6 } & $a=0.036$ & - & $L_{\text {norm }}<0.04$ & $0.04 \leq L_{\text {norm }} \leq 0.54$ & $0.54<L_{\text {norm }}$ \\
\hline \multirow{3}{*}{$1 / m$} & $a=0.042$ & - & $L_{\text {norm }}<0.04$ & $0.04 \leq L_{\text {norm }} \leq 0.52$ & $0.52<L_{\text {norm }}$ \\
\cline { 2 - 6 } & $a=0.050$ & - & $L_{\text {norm }}<0.06$ & $0.06 \leq L_{\text {norm }} \leq 0.52$ & $0.52<L_{\text {norm }}$ \\
\hline \hline \multirow{3}{*}{$3 / m$} & $a=0.107$ & $L_{\text {norm }}<0.09$ & $0.09 \leq L_{\text {norm }} \leq 0.15$ & $0.15<L_{\text {norm }} \leq 0.54$ & $0.54<L_{\text {norm }}$ \\
\cline { 2 - 6 } & $a=0.125$ & $L_{\text {norm }}<0.12$ & $0.12 \leq L_{\text {norm }} \leq 0.17$ & $0.17<L_{\text {norm }} \leq 0.54$ & $0.54<L_{\text {norm }}$ \\
\cline { 2 - 7 } & $a=0.150$ & $L_{\text {norm }}<0.16$ & $0.16 \leq L_{\text {norm }} \leq 0.21$ & $0.21<L_{\text {norm }} \leq 0.52$ & $0.52<L_{\text {norm }}$ \\
\hline \hline \multirow{3}{*}{$5 / m$} & $a=0.179$ & $L_{\text {norm }} \leq 0.21$ & $0.21<L_{\text {norm }} \leq 0.29$ & $0.29<L_{\text {norm }} \leq 0.52$ & $0.52<L_{\text {norm }}$ \\
\cline { 2 - 6 } & $a=0.208$ & $L_{\text {norm }} \leq 0.25$ & $0.25 \leq L_{\text {norm }} \leq 0.33$ & $0.33<L_{\text {norm }} \leq 0.50$ & $0.50<L_{\text {norm }}$ \\
\cline { 2 - 6 } & $a=0.250$ & $L_{\text {norm }}<0.31$ & $0.31 \leq L_{\text {norm }} \leq 0.41$ & $0.41<L_{\text {norm }} \leq 0.50$ & $0.50<L_{\text {norm }}$ \\
\hline
\end{tabular}

Table A.1: Post-buckling responses of $\left[\left(0^{\circ} / 90^{\circ}\right)_{\mathrm{s}}\right]_{n}$ laminates with $n=\{5,6,7\}$ for varying delamination depths and lengths; $m$ - total amount of layers in laminate. 


\section{Appendix B. ERR for delamination growth}

The behaviour of the ERR for delamination growth is visualized for all cases studied in Fig. B.1. The ERR $\left(G_{\text {norm }}\right)$ is plotted against delamination length $\left(L_{\text {norm }}\right)$ for increasing levels of load input $\mathcal{E}_{\text {norm }}$ for all delamination depths $(a)$. The results are presented for each laminate studied: $\left[\left(0^{\circ} / 90^{\circ}\right)_{\mathrm{s}}\right]_{n}, n=7,6,5$, in Figs. B.1a, B.1b and B.1c, respectively.

A detailed overview about configurations causing stable and unstable delamination growth is provided in Table B.1. Note that in certain configurations the energy release rate for delamination growth might not reach the critical magnitude required during the deformation process studied. Also, the quantities provided are based on the assumption that the critical threshold is $G_{\text {norm }}=1$. The unstable region provided in Table B.1 considers the largest delamination length studied in the current work of $L_{\text {norm }}=0.725$. It should be noted, in particular for delamination depth $5 / m$, that larger delamination lengths may exhibit similar characteristics as observed in the case $a=0.250$ ( $c f$. [18, 20] for delamination depth $a>0.250)$.

\begin{tabular}{|c|c|c|c|}
\hline \multirow{2}{*}{\multicolumn{2}{|c|}{$\begin{array}{c}\text { depth } a \\
m=\{28,24,20\}\end{array}$}} & \multicolumn{2}{|c|}{ delamination growth behaviour } \\
\hline & & stable & unstable \\
\hline \multirow{3}{*}{$1 / m$} & $a=0.036$ & $0.04 \leq L_{\text {norm }}<0.54$ & $0.02 \leq L_{\text {norm }}<0.04 ; 0.54 \leq L_{\text {norm }}<L_{\max }$ \\
\hline & $a=0.042$ & $0.04 \leq L_{\text {norm }}<0.52$ & $0.02 \leq L_{\text {norm }}<0.04 ; 0.52 \leq L_{\text {norm }}<L_{\max }$ \\
\hline & $a=0.050$ & $0.04 \leq L_{\text {norm }}<0.52$ & $0.02 \leq L_{\text {norm }}<0.04 ; 0.52 \leq L_{\text {norm }}<L_{\max }$ \\
\hline \multirow{3}{*}{$3 / m$} & $a=0.107$ & $0.17 \leq L_{\text {norm }}<0.52$ & $0.12 \leq L_{\text {norm }}<0.17 ; 0.52 \leq L_{\text {norm }}<L_{\max }$ \\
\hline & $a=0.125$ & $0.17 \leq L_{\text {norm }}<0.50$ & $0.12 \leq L_{\mathrm{norm}}<0.17 ; 0.50 \leq L_{\mathrm{norm}}<L_{\max }$ \\
\hline & $a=0.150$ & $0.16 \leq L_{\text {norm }}<0.50$ & $; 0.50 \leq L_{\text {norm }}<L_{\max }$ \\
\hline \multirow{3}{*}{$5 / m$} & $a=0.179$ & $0.33 \leq L_{\text {norm }}<0.62$ & $0.23 \leq L_{\text {norm }}<0.33 ; 0.62 \leq L_{\text {norm }}<L_{\max }$ \\
\hline & $a=0.208$ & $0.31<L_{\text {norm }}<0.56$ & $0.26 \leq L_{\mathrm{norm}} \leq 0.31 ; 0.56 \leq L_{\mathrm{norm}}<L_{\max }$ \\
\hline & $a=0.250$ & $0.31<L_{\text {norm }}<0.54$ & $; 0.56 \leq L_{\text {norm }}<0.66^{*}$ \\
\hline
\end{tabular}

Table B.1: Regions of stable and unstable delamination growth behaviour for all laminates investigated $\left(\left[\left(0^{\circ} / 90^{\circ}\right)_{\mathrm{s}}\right]_{n}\right.$ with $\left.n=\{5,6,7\}\right)$ for varying delamination depths; $m$ - total amount of layers in laminate; $L_{\max }=0.73$.

Based on the information provided in Fig. B.1 and Table B.1, the delamination growth behaviour has been summarized in Fig. 8 in Section 3.3.1 indicating regions of stable and unstable delamination growth. 


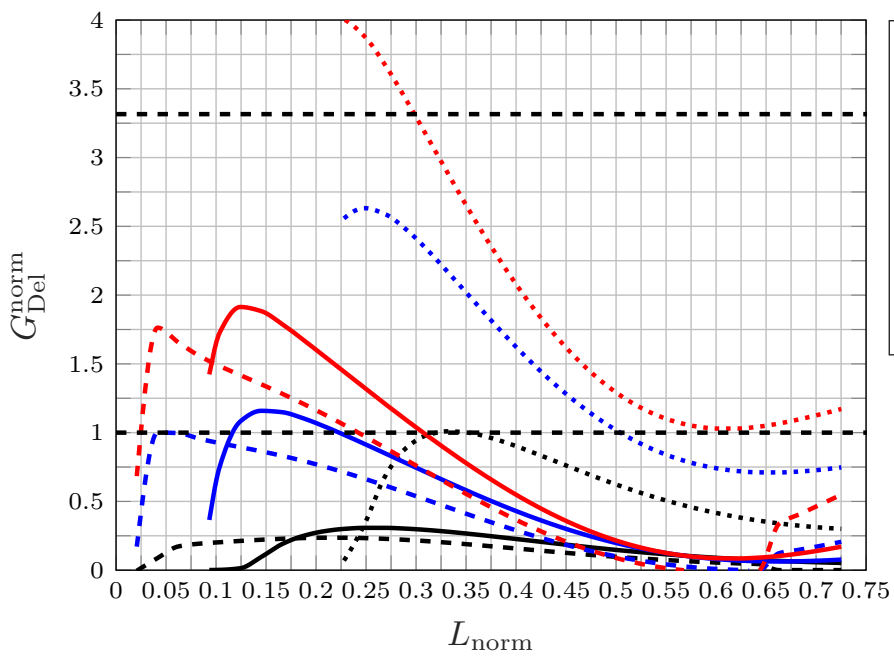

$$
\begin{aligned}
& \text { - - } a=0.036, \mathcal{E}_{\text {norm }}=0.83 \\
&-a=0.107, \mathcal{E}_{\text {norm }}=0.83 \\
& \cdots \ldots a=0.179, \mathcal{E}_{\text {norm }}=0.83 \\
&---a=0.036, \mathcal{E}_{\text {norm }}=1.12 \\
&-a=0.107, \mathcal{E}_{\text {norm }}=1.12 \\
& \ldots \ldots a=0.179, \mathcal{E}_{\text {norm }}=1.12 \\
&---a=0.036, \mathcal{E}_{\text {norm }}=1.33 \\
&-a=0.107, \mathcal{E}_{\text {norm }}=1.33 \\
& \ldots a=0.179, \mathcal{E}_{\text {norm }}=1.33
\end{aligned}
$$

(a) Laminat $\left[\left(0^{\circ} / 90^{\circ}\right)_{\mathrm{s}}\right]_{7}$

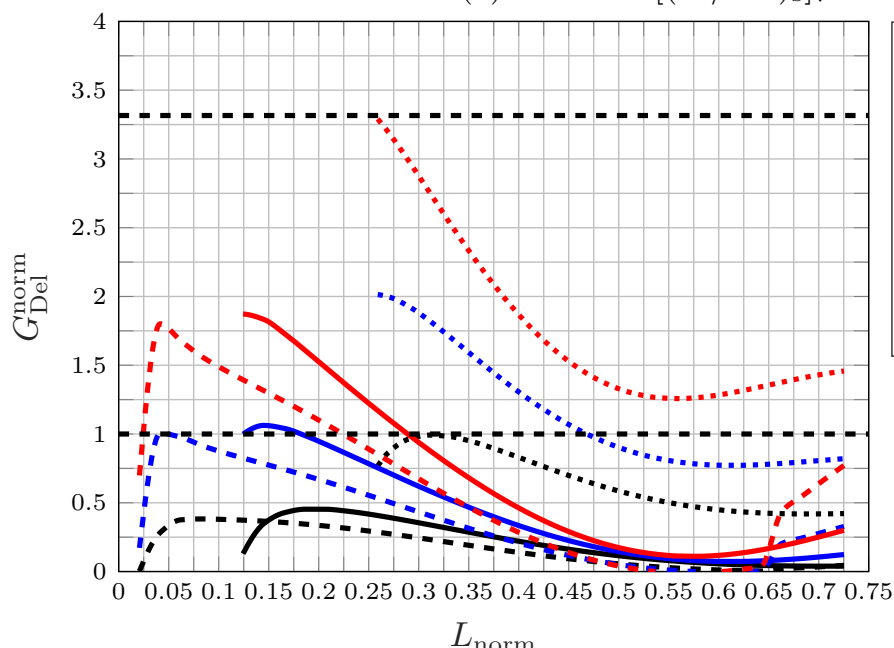

- - - $a=0.042, \mathcal{E}_{\text {norm }}=1.03$

$\longrightarrow a=0.125, \mathcal{E}_{\text {norm }}=1.03$

$\ldots \ldots a=0.208, \mathcal{E}_{\text {norm }}=1.03$

- - - $a=0.042, \mathcal{E}_{\text {norm }}=1.36$

$\longrightarrow a=0.125, \mathcal{E}_{\text {norm }}=1.36$

$\ldots \ldots a=0.208, \mathcal{E}_{\text {norm }}=1.36$

- = $a=0.042, \mathcal{E}_{\text {norm }}=1.83$

$a=0.125, \mathcal{E}_{\text {norm }}=1.83$

$\ldots a=0.208, \mathcal{E}_{\text {norm }}=1.83$

(b) Laminat $\left[\left(0^{\circ} / 90^{\circ}\right)_{\mathrm{s}}\right]_{6}$

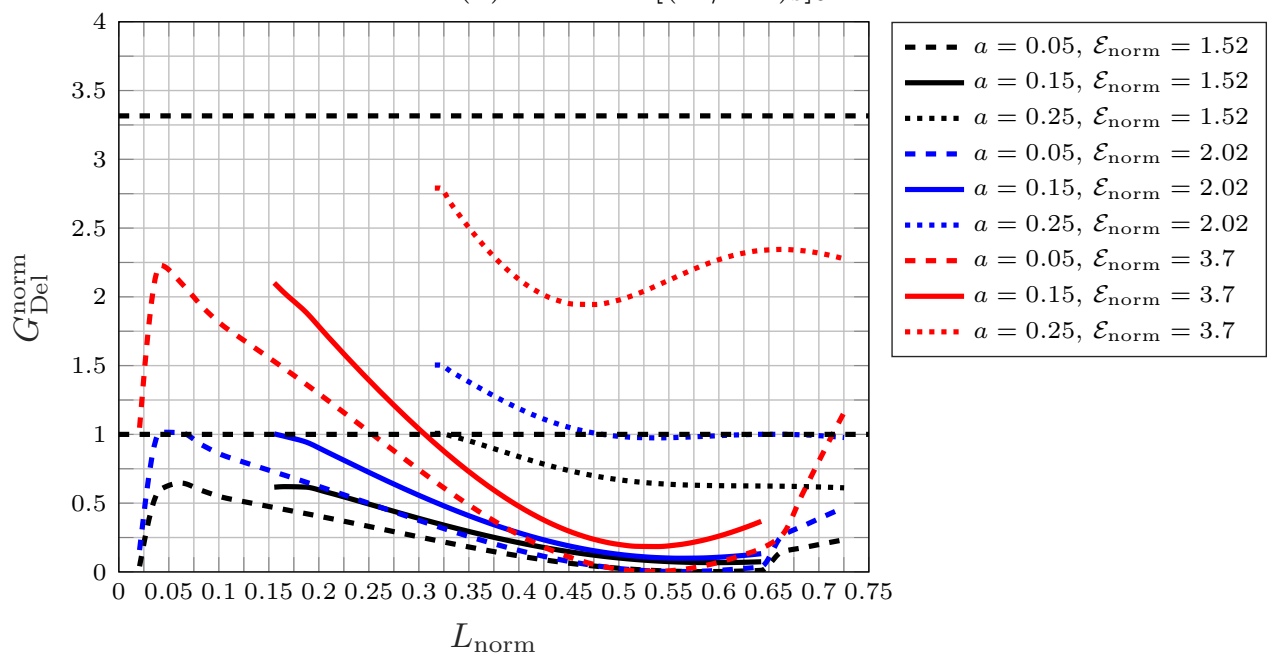

(c) Laminat $\left[\left(0^{\circ} / 90^{\circ}\right)_{\mathrm{s}}\right]_{5}$

Figure B.1: Normalized energy release rate for delamination growth $G_{\text {del }}^{\text {norm }}$ against normalized delamination length $L_{\text {norm }}$ for increasing levels of load input (normalized end-shortening $\mathcal{E}_{\text {norm }}$ ) and varying delamination depth $a$. 


\section{Appendix C. ERR against delamination length and compressive force}

In Fig. C.1, the ERR for delamination growth $\left(G_{\text {del }}^{\text {norm }}\right)$ is shown against the delamination length $\left(L_{\text {norm}}\right)$ for increasing values of compressive force $\left(P_{\text {norm }}=\right.$ $\{0.867,0.877,0.884,0.886\})$, i.e. for the case of a force controlled system. The energy release rate is normalized against the critical ERR of Mode I $\left(G_{\mathrm{c}}^{\mathrm{I}}=0.19\right.$ $\mathrm{N} / \mathrm{mm}$ ), the compressive force against the Euler buckling load of the intact strut and the delamination length against the total length.

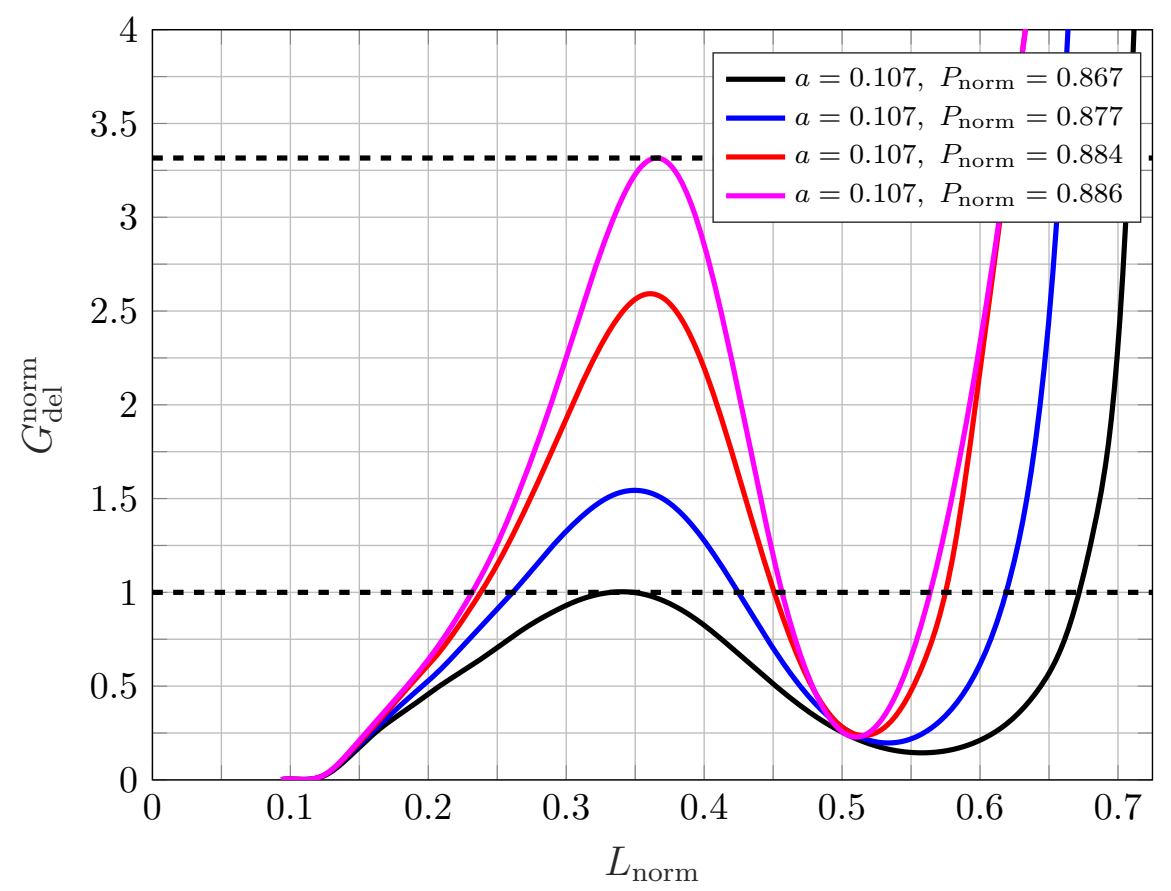

Figure C.1: Behaviour of the energy release rate for delamination growth against delamination length for increasing compressive forces; laminate: $\left[\left(0^{\circ} / 90^{\circ}\right)_{\mathrm{s}}\right]_{7}, a=3 / 28$; in normalized quantities.

The behaviour of the ERR in a force controlled system exhibits similarities and deviations compared with the displacement controlled case shown in Fig. 7. The initial region of increasing ERR spreads over a larger span of delamination lengths (up to $L_{\text {norm }} \approx 0.34$ ). On the other hand, delamination lengths associated with stable delamination propagation are limited to $L_{\text {norm }} \approx 0.34-0.52$. This is because the characteristic minimum identified in Section 3.3.1 is also given for the force controlled system. Larger delamination lengths than $L_{\text {norm }} \approx 0.52$ are also associated with unstable delamination growth. However, the load level lines in 
Fig. C.1 represent just a marginally increase in applied compressive force, since the ERR reaches its critical values ( $c f$. horizontal dashed lines in Fig. C.1) once global buckling occurred.

\section{Appendix D. Finite element model}

The finite element (FE) model used for verifying the analytical modelling approach is presented in Fig. D.1, where Fig. D.1a shows the model along with the boundary conditions, Fig. D.1b the mesh and Fig. D.1c the nodes assigned to the virtual crack closure technique (VCCT) in order to model the delamination growth behaviour. Note that for illustration purposes Figs. D.1b and D.1c show only half of the strut exploiting the symmetry of the problem.

The FE model (Fig. D.1a) consists of two parts (planar shells) having the layup of the upper and lower sublaminate respectively. Surface to surface contact between the upper face of the lower sublaminate and the lower face of the upper sublaminate is configured, where bonding between both parts is enforced by identifying nodes in the intact region of the strut ( $c f$. Fig. D.1c) for which the virtual crack closure technique (VCCT) is employed to model delamination growth. The B-K-law [2] as implemented in Abaqus is adjusted to provide a mode I crack growth criterion. Thus, delamination growth is initiated whenever the $\operatorname{ERR}(G)$ reaches the critical ERR for mode I $\left(G_{\mathrm{c}}^{\mathrm{I}}\right)$. A precise prediction of the onset of delamination growth is enabled by setting the tolerance value in the VCCT to $0.1 \%$. Regarding closed mode buckling responses of type A (cf. Section 3.2), as done in the analytical model, the analysis is stopped whenever both sublaminates get in contact with each other.

Loading in the form of end-shortening is applied to the strut by configuring kinematic coupling between the edges of both sublaminates and a reference point (RP; cf. Fig. D.1a), where the reference point follows a monotonically increasing displacement (end-shortening $\mathcal{E}$ ) up to the initiation of delamination growth.

The boundary conditions for a both sided clamped strut are provided in Fig. D.1a using the notation as implemented in Abaqus, where $U 1$ ( $u$ in Section 2.2) and $U 2$ are the in-plane displacements in $x$ and $y$-direction respectively and $U 3$ ( $w$ in Section 2.2) describes the out-of-plane displacement ( $z$-direction). The rotations around the $x, y$ and $z$-axis are denoted by $U R 1, U R 2$ and $U R 3$ respectively. 


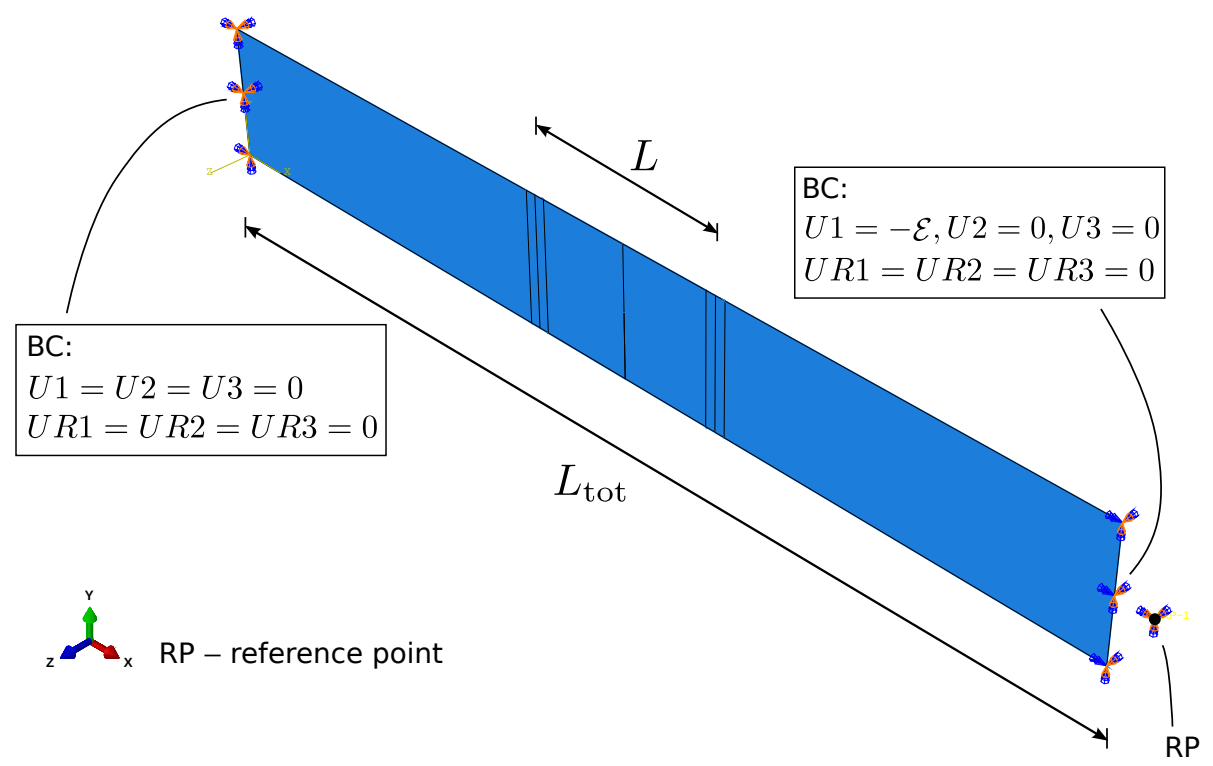

(a) FE model with boundary conditions.

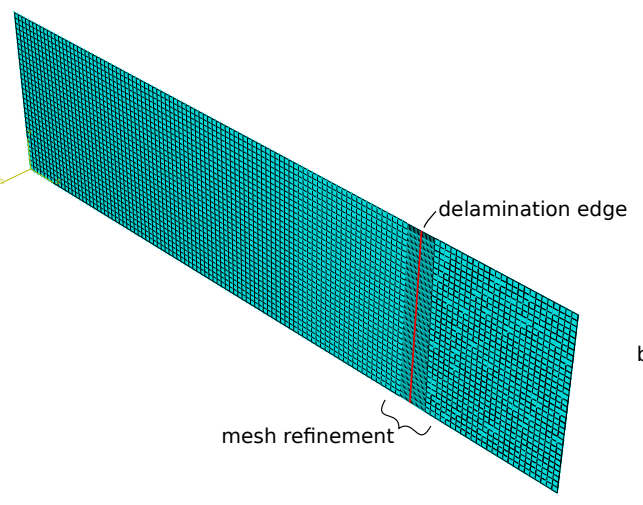

(b) Mesh of the FE model.

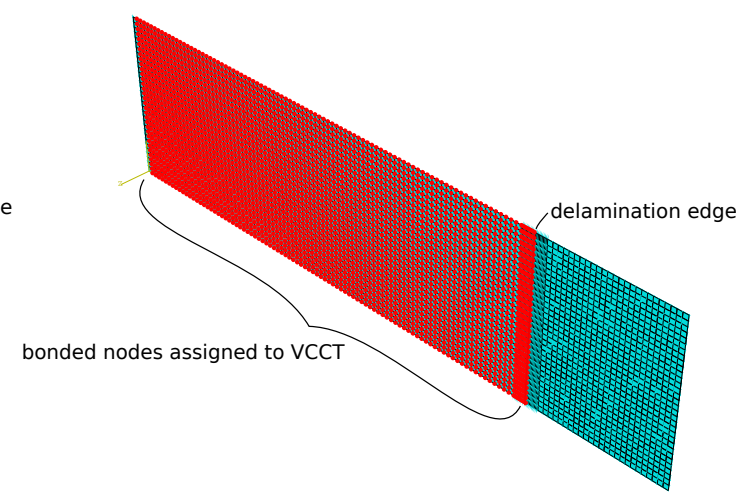

(c) Nodes assigned to VCCT.

Figure D.1: FE model of a delaminated composite strut. 
Each sublaminate is built-up by shell elements (type S4R) with an element size of $0.4 \mathrm{~mm}$. Mesh refinement around the delamination tips to $0.09 \mathrm{~mm}$ is employed (cf. Fig. D.1b) which is approximately the thickness of a single ply. The FE model comprises in total 17408 elements.

\section{References}

[1] Abir, M.R., Tay, T.E., Ridga, M., Lee, H.P., 2017. Modelling damage growth in composites subjected to impact and compression after impact. Compos Struct 168, 13-25.

[2] Benzeggagh, M.L., Kenane, M., 1996. Measurement of mixed-mode delamination fracture toughness of unidirectional glassepoxy composites with mixedmode bending apparatus. Compos Sci Tech 56, 439-449.

[3] Butler, R., Rhead, A.T., Liu, W., Kontis, N., 2012. Compressive strength of delaminated aerospace composites. Phil Trans R Soc Lond A 370, 1759-1779.

[4] Chai, H., Babcock, C.D., Knauss, W.G., 1981. One dimensional modelling of failure in laminated plates by delamination buckling. Int J Solids Struct 17, 1069-1083.

[5] Choudhry, R.S., Rhead, A.T., Nielsen, M.W.D., Butler, R., 2019. A plate model for compressive strength prediction of delaminated composites. Compos Struct 210, 509-517.

[6] Hashin, Z., 1987. Analysis of orthogonally cracked laminates under tension. J Appl Mech-T ASME 25, 771-778.

[7] Henaff-Gardin, C., Lafarie-Frenot, M.C., Gamby, D., 1996. Doubly periodic matrix cracking in composite laminates part 1: general in-plane loading. Compos Struct 36, 113-130.

[8] Huang, H., Kardomateas, G.A., 1998. Buckling of orthotropic beam-plates with multiple central delaminations. Int J Solids Struct 35, 1355-1362.

[9] Hunt, G.W., Hu, B., Butler, R., Almond, D.P., Wright, J.E., 2004. Nonlinear modeling of delaminated struts. AIAA Journal 42, 2364-2372. 
[10] İpek, G., Arman, Y., Çelik, A., 2018. The effect of delamination size and location to buckling behavior of composite materials. Composites B 155, $69-76$.

[11] Kardomateas, G.A., 1993. The initial post-buckling and growth behaviour of internal delaminations in composite plates. J Appl Mech 60, 903-910.

[12] Kashtalyan, M., Soutis, C., 2000. Stiffness degradation in cross-ply laminates damaged by transverse cracking and splitting. Composites A 31, 335-351.

[13] Kashtalyan, M., Soutis, C., 2013. Predicting residual stiffness of cracked composite laminates subjected to multi-axial in-plane loading. J Compos Mater 47, 2513-2524.

[14] Kashtalyan, M., Soutis, C., 2016. Modelling of stiffness degradation due to cracking in laminates subjected to multi-axial loading. Philos TransRoyal Soc A 374, 20160017.

[15] Katerelos, D.T.G., Kashtalyan, M., Soutis, C., Galiotis, C., 2008. Matrix cracking in polymeric composites laminates: Modelling and experiments. Compos Sci Technol 68, 2310-2317.

[16] Köllner, A., 2017. An analytical framework for the structural stability analysis of damageable structures and its application to delaminated composites. Dissertation. Technische Universität Berlin.

[17] Köllner, A., Forsbach, F., Völlmecke, C., 2019. Delamination buckling in composite plates: an analytical approach to predict delamination growth, in: Abali, B.E., Altenbach, H., dell'Isola, F., Eremeyev, V., Öchsner, A. (Eds.), New Achievements in Continuum Mechanics and Thermodynamics. Springer. volume 108 of Advanced Structured Materials.

[18] Köllner, A., Jungnickel, R., Völlmecke, C., 2016. Delamination growth in buckled composite struts. Int J Fract 202, 261-269.

[19] Köllner, A., Kashtalyan, M., Guz, I., Völlmecke, C., 2018. Modelling cracked cross-ply laminates with delamination buckling. Key Eng Mater 774, 60-65. 
[20] Köllner, A., Völlmecke, C., 2017a. An analytical framework to extend the general structural stability analysis by considering certain inelastic effectstheory and application to delaminated composites. Compos Struct 170, 261270 .

[21] Köllner, A., Völlmecke, C., 2017b. Buckling and postbuckling behaviour of delaminated composite struts. Int J Comput Meth Eng Sci Mech 18, 25-33.

[22] Köllner, A., Völlmecke, C., 2018. Post-buckling behaviour and delamination growth characteristics of delaminated composite plates. Compos Struct 203, $777-788$.

[23] Krueger, R., 2004. Virtual crack closure technique: History, approach, and applications. Appl Mech Rev 57, 109-143.

[24] Kutlu, Z., Chang, F.K., 1992. Modeling compression failure of laminated composites containing multiple through-the-width delaminations. J Compos Mater 26, 350-387.

[25] Liu, P.F., Hou, S.J., Chu, J.K., Hu, X.Y., Zhou, C.L., Liu, J.L., Zheng, J.Y., Zhao, A., Yan, L., 2011. Finite element analysis of postbuckling and delamination of composite laminates using virtual crack closure technique. Compos Struct 93, 1549-1560.

[26] Mohammadi, B., Shahabi, F., 2016. On computational modeling of postbuckling behavior of composite laminates containing single and multiple throughthe-width delaminations using interface elements with cohesive law. Eng Fract Mech 152, 88-104.

[27] Nikrad, S.F., Keypoursangsari, S., Asadi, H., Akbarzadeh, A.H., Chen, Z.T., 2016. Computational study on compressive instability of composite plates with off-center delaminations. Comput Methods in Appl Mech Eng 310, 429-459.

[28] Nilsson, K.F., Asp, L.E., Alpman, J.E., Nystedt, L., 1993. A theoretical and experimental investigation of buckling induced delamination growth. J Mech Phys Solids 41, 749-782. 
[29] Ovesy, H.R., Kharazi, M., 2011. Compressional stability behavior of composite plates with through-the-width and embedded delaminations by using first order shear deformation theory. Comput Struct 89, 1829-1839.

[30] Reddy, J.N., 2004. Mechanics of laminated composite plates and shells: theory and analysis. CRC press.

[31] Rhead, A.T., Butler, R., Hunt, G.W., 2017. Compressive strength of composite laminates with delamination-induced interaction of panel and sublaminate buckling modes. Compos Struct 171, 326-334.

[32] Rivallant, S., Bouvet, C., Abdallah, E.A., Broll, B., Barrau, J.J., 2014. Experimental analysis of CFRP laminates subjected to compression after impact: The role of impact-induced cracks in failure. Comput Struct 11, 147-157.

[33] Sheinman, I., Kardomateas, G.A., Pelegri, A.A., 1998. Delamination growth during pre- and post-buckling phases of delaminated composite laminates. Int J Solids Struct 35, 19-31.

[34] Sheinman, I., Soffer, M., 1991. Delamination growth during pre- and postbuckling phases of delaminated composite laminates. Int J Solids Struct 27, 639-646.

[35] Sun, X.C., Hallet, S.R., 2018. Failure mechanisms and damage evolution of laminated composites under compression after impact (cai): experimental and numerical study. Composites Part A 104, 41-59.

[36] Tan, W., Falzon, B.G., Chiu, L.N.S., Price, M., 2016. Predicting low velocity impact damage and compression-after-impact(cai) behaviour of composite laminates. Composites Part A 71, 212-226.

[37] Thompson, J.M.T., Hunt, G.W., 1984. Elastic instability phenomena. John Wiley \& Sons.

[38] Wang, K., Zhao, L., Hing, H., Gong, Y., Zhang, J., Hu, N., 2019. An analytical model for evaluating the buckling, delamination propagation, and failure behaviors of delaminated composites under uniaxial compression. Compos Struct 223, 110937. 
[39] Xia, F., Jian, F., Zhu, Z., Li, P., Liang, H., Jin, F., 2019. A modified first order shear deformation theory for reissner-mindlin composite panels with internal delamination. Compos Struct 224, 110935.

[40] Yin, W.L., Sallam, S., Simitses, G.J., 1986. Ultimate axially load capacity of delaminated beam-plate. AIAA Journal 24, 123-128.

[41] Zhang, J., Fan, J., C., S., 1992. Analysis of multiple matrix cracking in composite laminates part 1: in-plane stiffness properties. Composites 23, 291-298.

[42] Zhang, J., Fan, J., P., H.K., 1999. Delaminations induced by constrained transverse cracking in symmetric composite laminates. Int J Solids Struct 36, 813-846. 